\title{
Geografía de las Plantas en La Alcarria Occidental y Mesa de Ocaña (y III). Análisis de procedencia en cinco localidades representativas
}

\author{
Juan Javier GARCÍA-ABAD ALONSO \\ Departamento de Geografía. Universidad de Alcalá \\ juanj.garciaabad@uah.es
}

Recibido: 3 de noviembre de 2012

Enviado a evaluar: 22 de enero de 2013

Aceptado: 12 de marzo de 2013

\begin{abstract}
RESUMEN
A partir de inventarios florísticos efectuados en el año hidrológico 2002-03 en cinco cuadrículas U.T.M. de $1 \mathrm{~km}^{2}$, que forman un transecto representativo en La Alcarria Occidental y Mesa de Ocaña (AM), se continúa el análisis de espectros biológicos iniciado en trabajos anteriores (García-Abad, 2009 y 2011, Partes I y II). Se trata el criterio biogeográfico y se discriminan las plantas autóctonas de las alóctonas y su diferente procedencia. A su vez, se discriminan las plantas invasoras de las no invasoras, de acuerdo a la propuesta de Sanz et al. (2004). Los espectros obtenidos se relacionan con los correspondientes al conjunto de AM, gracias al anidamiento territorial efectuado. Se presenta un listado provisional de plantas alóctonas en AM.
\end{abstract}

Palabras clave: Cuadrícula U.T.M. de $1 \mathrm{~km}^{2}$. Espectro biogeográfico. Plantas alóctonas. Plantas invasoras. La Alcarria Occidental y Mesa de Ocaña.

\section{Plant Geography of Western La Alcarria and "Mesa" of Ocaña (III). Prove- nance analysis of five representative space tracts}

\begin{abstract}
Biological spectra analysis initiated in previous papers (García-Abad, 2009 and 2011, Parts I and II) is continued here. Floristic inventories are carried out during one agricultural year (2002-03) in five $1 \mathrm{~km}^{2}-$ U.T.M. grid squares. These space tracts form a representative transect in Western La Alcarria and "Mesa" of Ocaña (AM). This Part III is about the biogeographical spectrum. We discriminate between native and no-native plants and analyze their provenance. In turn, Sanz et al. (2004) criteria were designed to discriminate between invasive alien and no-invasive alien plants. Since the both spaces are nested, locally determinated spectra could be related to the spectra of AM region. Finally, we present a provisional checklist of alien plants of AM.
\end{abstract}

Key words: $1 \mathrm{~km}^{2}$ U.T.M. grid cell. Biogeographical spectrum. Alien plants. Invasive alien plants. Natural region of Western La Alcarria and "Mesa" de Ocaña. 


\section{Géographie des plantes de La Alcarria de l'Ouest et "Mesa" d'Ocaña (II). Analyse de provenance à cinq localités représentatives}

\section{RÉSUMÉ}

À partir des relevés floristiques effectués dans l'année agrologique 2002-03 à cinq carrés U.T.M. de $1 \mathrm{~km}^{2}$, formant un transect représentatif dans la región naturelle de La Alcarria de l'Ouest et "Mesa" d'Ocaña (AM), cet article continue comme troisième de sa série (GarcíaAbad, 2009 et 2011, Parts I et II) l'analyse de spectres biologiques. Le critère biogéographique est appliqué ici. Les xenophytes sont distingués des plantes indigènes et tous les deux provenances géographiques sont analysées. À son tour, la distinction est effectuée entre les plantes invasives et les non invasives, selon le critère de Sanz et al. (2004). Les spectres obtenus se rattachent aux correspondants à l'ensemble d'AM, grâce à l'établissement des espaces imbriqués. Une liste provisoire des xénophytes d'AM est montré.

Mots clés: Carré U.T.M. de $1 \mathrm{~km}^{2}$. Spectre biogéographique. Xénophytes. Plantes invasives. Region naturelle de La Alcarria de l'Ouest et "Mesa" d'Ocaña.

\section{INTRODUCCIÓN}

En tres trabajos anteriores se estudiaron diferentes aspectos de la flora de La Alcarria Occidental y Mesa de Ocaña (AM, a partir de ahora), y de cinco localidades que eran representativas de sus rasgos geográficos típicos (García-Abad, 2006, 2009 y 2011). Éstas consistieron en cinco cuadrículas U.T.M. de $1 \mathrm{~km}^{2}$ (ED50) separadas geográficamente de manera más o menos equidistante, según un criterio de selección que aportaba cierto poder predictivo, pues son típicas del paisaje alcarreño-ocañense. En ellas dominaban los ambientes zonales y/o climácicos (seminaturales y agrarios asociados) y se evitaron en buena medida los azonales y/o extremos. En conjunto muestran sintéticamente buena parte de los gradientes climáticos, topográficos, litológicos, geomorfológicos y edafológicos de aquella región natural. Las localidades fueron las siguientes (Figura 1): C1 (30TWL0624), municipios de Utande y Miralrío (Guadalajara); C2 (30TVK9395), Lupiana (Guadalajara); C3 (30TVK8264), Villar del Olmo y Ambite (Madrid); C4 (30TVK7136), Villarrubia de Santiago (Toledo); y C5 (30SVK6207), La Guardia (Toledo).

Los antecedentes, la caracterización geográfica de AM (región natural de unos $6.700 \mathrm{~km}^{2}$ ), los rasgos geográficos de cada una de estas cuadrículas, su semblanza fitogeográfica, el método empleado, las plantas inventariadas en ellas, los espectros taxonómico, fitoecológico, biotípico y vegetativos de la flora autóctona, interpretaciones geoecológicas; así como varias discusiones ya fueron expuestos ampliamente en García-Abad (2006, 2009 y 2011). El análisis de semejanza florística efectuado en la Parte I (García-Abad, 2009) reveló que, en un primer nivel de desagregación geográfica, C1, C2 y C3 forman un sector centro-septentrional (pisos supra y mesomediterráneo) algo diferenciado respecto al meridional (piso exclusivamente mesomediterráneo), constituido por C4 y C5. Esta cesura fundamental se mantiene a grandes rasgos cuando en la Parte II (García-Abad, 2011) se analizaron espectros diferentes al taxonómico, aunque se incorporan algunas excepciones y matices de detalle que tienen sumo interés fitogeográfico. 
El presente artículo, con el que se concluye todo el estudio, es continuación de los tres trabajos referidos. Por tanto, se recomienda la consulta previa de esas publicaciones para facilitar la comprensión de lo que aquí se expondrá.

Figura 1. Situación de las cinco cuadrículas de $1 \mathrm{~km}^{2}$

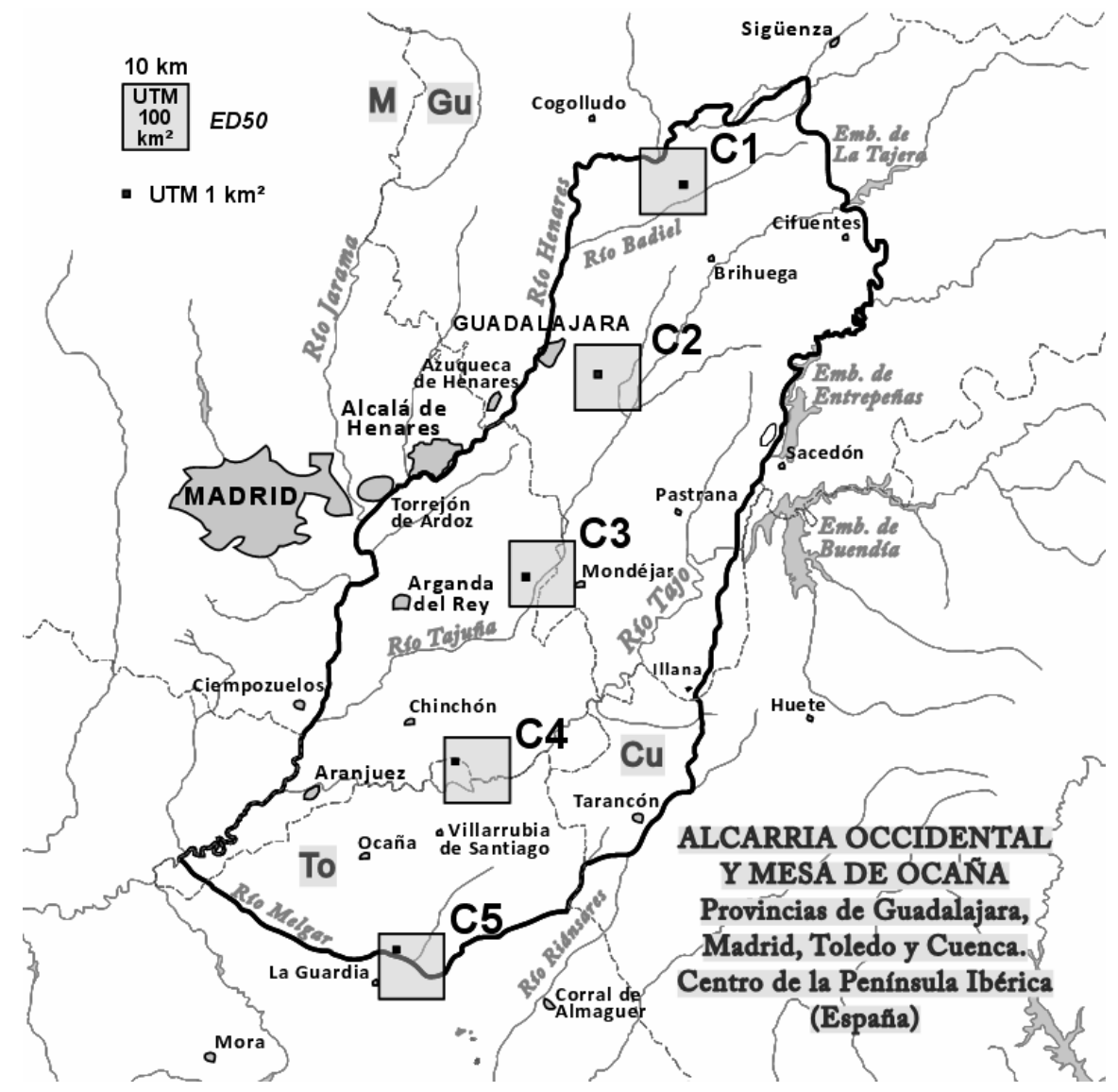

Fuente: García-Abad (2009)

La Tabla 1 presenta la síntesis cuantitativa de la base de datos unificada y anidada, con la riqueza florística determinada a partir de recopilación de fuentes e inventarios propios en las unidades geográficas analizadas.

En AM, hasta el rango de variedad, suman un total de 1800 los táxones espontáneos (los autóctonos más los alóctonos naturalizados y asilvestrados). Si se añaden otros fanerófitos cultivados, la cifra alcanza los 1828 táxones. Pero, si además se añaden los híbridos, el cómputo alcanza las 1851plantas conocidas por citas ajenas y avistamientos propios. 
En el presente artículo, los objetivos específicos son: a) presentar el espectro biogeográfico de la flora autóctona de AM, a partir de una base de datos que recopila diferentes fuentes (actualizada hasta IX-2008); b) presentar el mismo espectro en esas cinco localidades, a partir del trabajo de campo en un ciclo anual completo (año hidrológico 2002-03); c) comparar los resultados de las diferentes unidades territoriales, teniendo en cuenta el anidamiento espacial, e interpretarlos fitogeográficamente; y d) discriminar la flora alóctona, invasora y no invasora, analizando sus espectros y comparándolos en los mismos términos.

Tabla 1: Cómputo de táxones y nothotáxones vasculares en La Alcarria Occidental y Mesa de Ocaña (actualizado hasta IX-2008), y en las cuadrículas del transecto efectuado en el año hidrológico 2002-2003.

\begin{tabular}{|r|c|c|r|r|r|r|r|r|r|}
\hline Unidades y Transecto $^{1}$ & A1 & A2 & \multicolumn{1}{c|}{ A3 } & B & C & D & H & I & TOTAL \\
\hline C1: 30T WL 0624 & 461 & 461 & 457 & 11 & 0 & $\mathbf{4 7 2}$ & 1 & 7 & $\mathbf{4 8 0}$ \\
C2: 30T VK 9395 & 440 & 440 & 435 & 9 & 4 & $\mathbf{4 5 3}$ & 1 & 10 & $\mathbf{4 6 0}$ \\
C3: 30T VK 8264 & 415 & 415 & 411 & 11 & 6 & $\mathbf{4 3 2}$ & 1 & 6 & $\mathbf{4 3 4}$ \\
C4: 30T VK 7136 & 308 & 308 & 306 & 2 & 1 & $\mathbf{3 1 1}$ & 3 & 1 & $\mathbf{3 1 4}$ \\
C5: 30S VK 6207 & 402 & 402 & 397 & 13 & 5 & $\mathbf{4 2 0}$ & 0 & 7 & $\mathbf{4 2 3}$ \\
\hline 5C & $\mathbf{6 9 0}$ & $\mathbf{6 9 0}$ & $\mathbf{6 8 1}$ & $\mathbf{2 3}$ & $\mathbf{7}$ & $\mathbf{7 2 0}$ & $\mathbf{4}$ & $\mathbf{1 7}$ & $\mathbf{7 3 2}$ \\
\hline AM & $\mathbf{1 6 3 4}$ & $\mathbf{1 6 1 1}$ & $\mathbf{1 5 4 3}$ & $\mathbf{8 6}$ & $\mathbf{8 0}$ & $\mathbf{1 7 7 7}$ & $\mathbf{2 4}$ & $\mathbf{2 8}$ & $\mathbf{1 8 5 1 *}$ \\
\hline
\end{tabular}

Fuentes: AM, (García-Abad (2006 y 2009); resto, trabajo de campo (año 2002-03).

\section{RESULTADOS}

\subsection{ESPECTRO BIOGEOGRÁFICO DE LA FLORA AUTÓCTONA}

El biogeográfico o corológico es uno de los espectros habituales en los trabajos fitogeográficos (Izco, 1969; Ron, 1970; Bolòs y Vigo, 1984-2001; Bolòs, 1986; Laorga, 1986; Costa, 1997; Aguilella y Mateo, 1998; Mateo, 1998; Meaza, 2000; Molero et al, 1998; Bartolomé et al., 2002; Gil y Costa, 2003; Navarro et al., 2003; Peñas et al., 2006; Lázaro, 2007; Rivas-Martínez y Cols., 2007; Peinado et al., 2008;

${ }^{1}$ Abreviaturas: A1, Táxones autóctonos hasta el rango de variedad. A2 subespecie. A3 especie. B, Táxones alóctonos adventicios y naturalizados (igual valor en los tres rangos). C, Táxones alóctonos asilvestrados de cultivo (idem). $\mathbf{D}=\mathbf{A} 2+\mathbf{B}+\mathbf{C}$ (Táxones espontáneos, hasta el rango de subespecie). H, Nothotáxones. I, Táxones y nothotáxones cultivados leñosos (y herbáceas vivaces fanerófitas). TOTAL $=(\mathrm{A} 1+\mathrm{B}+\mathrm{C}+\mathrm{H}+\mathrm{I})-$ Redundancias (cuando una misma planta se presenta con varios caracteres de cultivo, etc, se contabiliza una sola vez). 5C $=\mathrm{C} 1+\mathrm{C} 2+\mathrm{C} 3+\mathrm{C} 4+\mathrm{C} 5$. AM $=\mathrm{La}$ Alcarria Occidental y Mesa de Ocaña.

* La suma da 1851 , pues Populus $\times$ canadensis, contabilizada en $\mathrm{H}$ y en I, es redundante. 
Panareda y Boccio, 2009; Alcaraz, 2012; entre un larguísimo etcétera). Esto es, el espectro que considera el área de distribución de una planta, siendo normal contemplar la procedencia originaria natural de la misma, sin considerar las expansiones antropogénicas amplias.

En la Tabla 2 se presenta sintetizada en agrupaciones geográficas la flora autóctona de AM (sin híbridos), la del conjunto de las cinco cuadrículas (5C, a partir de ahora) y la de cada cuadrícula por separado, según aquel criterio. Se aplica de modo general el sistema biogeográfico de Mateo y Crespo (2002), completando táxones de AM que no están contemplados en esta obra, modificando algunas distribuciones y adaptando alguna nomenclatura a partir del cotejo de información suministrada por otras fuentes complementarias: Bolòs y Vigo (1984-2001), Castroviejo (1986-2008), Flora Iberica (web), Anthos (web) y Atlas de la Flora de Aragón (web). Los tipos aparecen en orden aproximado de mayor estenoicidad a mayor eurioicidad.

En las Figuras 2 y 3 se reducen a porcentajes los datos absolutos de la Tabla 2, empleando agrupaciones más sintéticas. El lector puede, con ellas, comparar los porcentajes teniendo en cuenta el anidamiento espacial de las unidades estudiadas.

El elemento endémico ibérico-balear en AM supone casi una décima parte de todas las plantas $(9,6 \%)$. Estos endemismos involucran a 34 familias, siendo 24 compuestas, 17 crucíferas, 15 cariofiláceas, 15 escrofulariáceas y 14 labiadas.

Ningún endemismo lo es del estricto territorio alcarreño-ocañense. En este sentido, AM no constituye un espacio florístico particularizado. En todo caso, hay cinco táxones cuya procedencia originaria se extiende algo más allá de AM por el Sur o/y por el Este: Limonium erectum, L. dichotomum, L. toletanum, Helianthemum marifolium subsp. conquensis y Brassica repanda subsp. gypsicola, correspondiéndoles en conjunto una corología manchega, obispaleña, altoalcarreña o/y bajomatritense, según la tipología corológica de Rivas-Martínez (2007).

En el conjunto $5 \mathrm{C}$, el porcentaje de endémicas ( $8 \%$ ) es algo más bajo que el regional. Pero, debido a la pequeñísima extensión que abarca $\left(5 \mathrm{~km}^{2}\right.$, frente a los 6.700 de AM) y a que se han encontrado el $35 \%$ de todos los endemismos, el transecto analizado puede considerarse bastante representativo del conjunto regional. Como endemismos más restringidos espacialmente, además del limonio toledano citado, sólo se encontraron otros tres táxones relevantes por su procedencia exclusiva del centro peninsular: Arenaria cavanillesiana, Centaurea toletana var. cavanillesiana y el gipsófito Thymus lacaitae.

En las cuadrículas por separado, destaca el que presenten una cifra relativamente alta de endemismos ibérico-baleares (más del 15\% de promedio de las presentes en AM en un solo kilómetro cuadrado). Compuestas y labiadas son las familias con más peso relativo entre ellos. El análisis geográfico de los datos revela que AM presenta una bipolaridad en la presencia de elementos endémicos; leve en términos absolutos (Tabla 2), pero suficientemente decantada en términos relativos (Figura 3). Consiste en que: a) el extremo septentrional, más influido por la Cordillera Ibérica; y, sobre todo, el sector meridional, influido por gipsofilia y por el Sistema Bético, concentran mayor endemicidad; y b) frente a ambos extremos, las dos cuadrículas intermedias 
madrileño-guadalajareñas ( $\mathrm{C} 2$ y C3) indican que el "corazón" alcarreño-ocañense es corológicamente algo menos particularista en este sentido.

Tabla 2. $\mathrm{N}^{\mathrm{o}}$ de táxones autóctonos (hasta variedad) según distribución geográfica

\begin{tabular}{|l|c|c|ccccc|}
\hline DISTRIBUCIÓN GEOGRÁFICA & AM & $\mathbf{5 C}$ & C1 & C2 & C3 & C4 & C5 \\
\hline Endemismo Ibérico (Centro) & 18 & 4 & 1 & 1 & & 2 & 3 \\
Endemismo Ibérico-Balear (C, S y E) & 43 & 21 & 8 & 5 & 5 & 8 & 9 \\
End. Ibérico-Balear amplio/disperso & 96 & 30 & 18 & 16 & 15 & 16 & 17 \\
Endemismos Ibérico-Baleares & $\mathbf{1 5 7}$ & $\mathbf{5 5}$ & $\mathbf{2 7}$ & $\mathbf{2 2}$ & $\mathbf{2 0}$ & $\mathbf{2 6}$ & $\mathbf{2 9}$ \\
Estenomediterránea Suroccidental & 110 & 39 & 16 & 18 & 23 & 23 & 27 \\
Estenomediterránea Noroccidental & 42 & 15 & 12 & 9 & 8 & 6 & 9 \\
Estenomediterránea Occidental & 134 & 68 & 45 & 40 & 49 & 40 & 43 \\
Estenomediterránea Meridional & 12 & 6 & 3 & 5 & 5 & 2 & 3 \\
Estenomediterránea Septentrional & 12 & 4 & 3 & 4 & 4 & 1 & 3 \\
Estenomediterránea & 187 & 89 & 64 & 61 & 63 & 46 & 54 \\
Eurimediterranea & 339 & 189 & 120 & 124 & 121 & 98 & 123 \\
Mediterránea y Atlántica & 27 & 6 & 6 & 5 & 5 & 2 & 3 \\
Mediterránea (amplia) & $\mathbf{8 6 3}$ & $\mathbf{4 1 6}$ & $\mathbf{2 6 9}$ & $\mathbf{2 6 6}$ & $\mathbf{2 7 8}$ & $\mathbf{2 1 8}$ & $\mathbf{2 6 5}$ \\
\hline Europea & 40 & 15 & 10 & 11 & 9 & 5 & 7 \\
Eurosiberiana y Boreal & 41 & 7 & 2 & 4 & 3 & 2 & 4 \\
Eurieurosiberiana y Euriboreal & 65 & 24 & 19 & 14 & 5 & 3 & 6 \\
Eurieuropea y Perieuropea & 119 & 43 & 32 & 33 & 30 & 15 & 22 \\
Europea/Eurieuropea/Perieuropea & $\mathbf{2 6 5}$ & $\mathbf{8 9}$ & $\mathbf{6 3}$ & $\mathbf{6 2}$ & $\mathbf{4 7}$ & $\mathbf{2 5}$ & $\mathbf{3 9}$ \\
\hline Euroasiática & 61 & 15 & 11 & 10 & 8 & 5 & 8 \\
Eurieuroasiática & 96 & 48 & 39 & 36 & 29 & 16 & 29 \\
Paleotemplada & 15 & 13 & 10 & 8 & 6 & 1 & 4 \\
Holoártica & 66 & 20 & 17 & 15 & 8 & 6 & 11 \\
Plurirregional y Euripantropical & 33 & 8 & 7 & 5 & 7 & 4 & 3 \\
Subcosmopolita & 46 & 15 & 8 & 9 & 6 & 2 & 8 \\
Cosmopolita & 12 & 7 & 7 & 3 & 4 & 2 & 4 \\
Ampliamente Supraeuropea & $\mathbf{3 2 9}$ & $\mathbf{1 2 6}$ & $\mathbf{9 9}$ & $\mathbf{8 6}$ & $\mathbf{6 8}$ & $\mathbf{3 6}$ & $\mathbf{6 7}$ \\
Desconocida o Incierta & $\mathbf{2 0}$ & $\mathbf{4}$ & $\mathbf{3}$ & $\mathbf{4}$ & $\mathbf{2}$ & $\mathbf{3}$ & $\mathbf{2}$ \\
\hline TOTAL TÁXONES AUTÓCTONOS & $\mathbf{1 6 3 4}$ & $\mathbf{6 9 0}$ & $\mathbf{4 6 1}$ & $\mathbf{4 4 0}$ & $\mathbf{4 1 5}$ & $\mathbf{3 0 8}$ & $\mathbf{4 0 2}$ \\
\hline
\end{tabular}

Fuentes AM, (García-Abad (2006 y 2009); resto, trabajo de campo (año 2002-03). 
Figura 2. Espectro biogeográfico de La Alcarria Occidental y Mesa de Ocaña

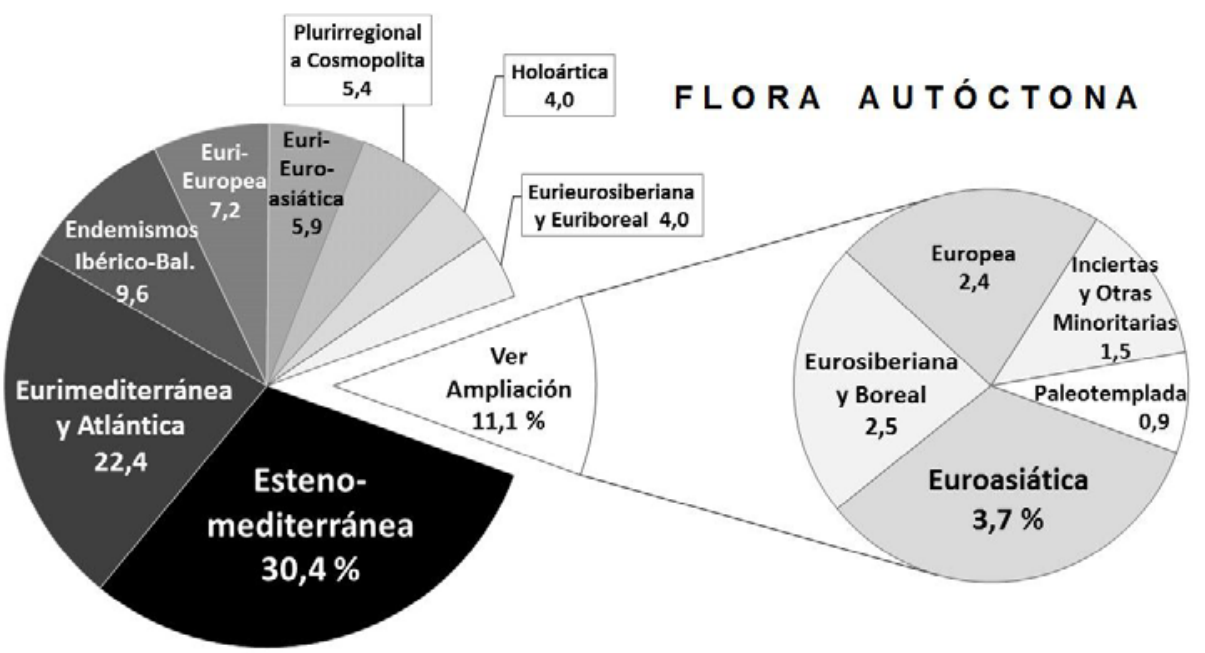

Fuentes: García-Abad (2006 y 2009). Elaboración propia

Figura 3. Espectros biogeográficos del conjunto 5C (en negro) y de las cuadrículas

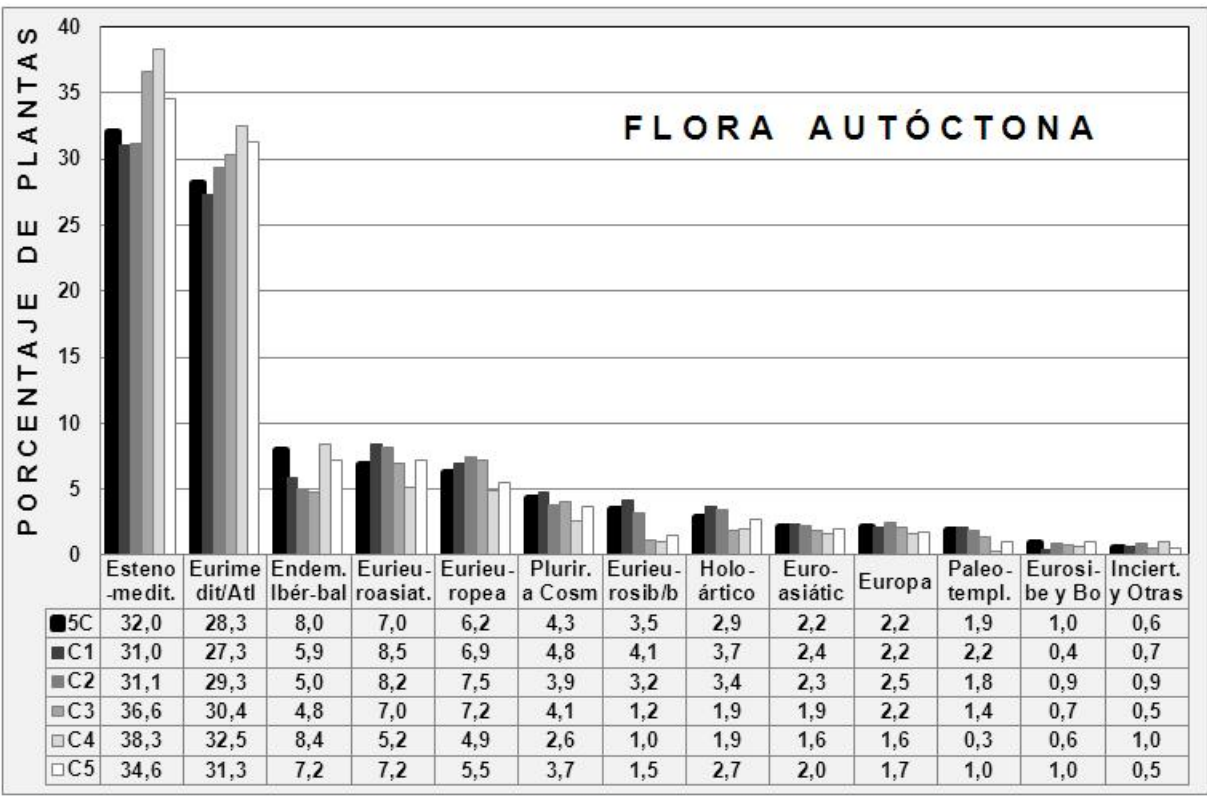

Fuentes: Trabajo de Campo. Elaboración propia 
Ésta es una importante pauta geográfico-florística en AM. Efectivamente, los tres primeros grupos de columnas de la Figura 3 muestran cómo los endemismos son más importantes en términos relativos en las cuadrículas meridionales respecto a las centro-septentrionales; mientras que transicionalmente las distribuciones mediterráneas lo son en las cuadrículas centro-meridionales respecto a las septentrionales.

Opuestamente, si se observa el resto de grupos de columnas de la Figura 3, estas cuadrículas septentrionales destacan por poseer, dentro del transecto, mayores porcentajes de las pocas plantas eurieurosiberianas que tiene AM. Esta pauta se extiende también a las de raigambre euroasiática a holoártica. Se aprecia también un comportamiento transicional de las cuadrículas centro-septentrionales, que poseen unos porcentajes mayores en plantas europeas y eurieuropeas respecto a las meridionales; $y$, ya menos significativamente, de plurirregionales a cosmopolitas.

Para visualizar con más claridad el gradiente biogeográfico que presenta AM de Norte a Sur, conviene agrupar los componentes corológicos mediterráneos y compararlos combinadamente con el resto (los supra y extramediterráneos). Así, en la Figura 4 se presentan cuatro agrupaciones que permiten una integración eurioica progresiva, indicando porcentajes parciales y acumulados.

Figura 4. Grupos más generales de distribución corológica (en porcentajes)

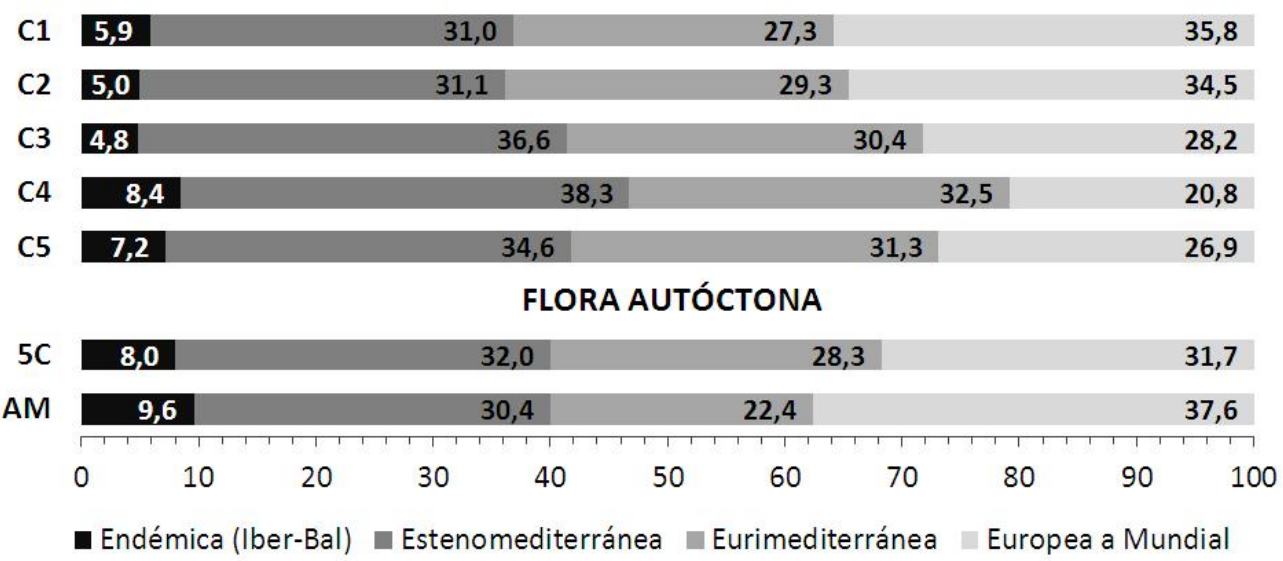

Fuentes: Elaboración propia, a partir de AM, (García-Abad (2006 y 2009); resto, trabajo de campo (año 2002-03).

En síntesis, al tratarse de un territorio plenamente mediterráneo desde un punto de vista bioclimático, AM posee un componente florístico mediterráneo amplio mayoritario $(62,4 \%$, endemismos incluidos) $\mathrm{o}$, si se prefiere, mediterráneo estricto dominante $(40 \%$, Idem). En este nivel de integración, curiosamente, coinciden plenamente los valores de $5 \mathrm{C}$ con los de $\mathrm{AM}$, lo que avala nuevamente la representatividad del transecto prospectado. A partir de ese nivel, el menor peso de las plantas supraextramediterráneas en $5 \mathrm{C}$ respecto a $\mathrm{AM}$ se explica probablemente por no haber cubierto el transecto sectores orientales (y, sobre todo, nororientales) de la región, 
cuya mayor proximidad a la Cordillera Ibérica hubiera aportado más plantas de raigambre de europea a eurieuroasiática.

Las dos cuadrículas septentrionales muestran valores muy coincidentes en el espectro biogeográfico general exhibido en la Figura 4. Tan sólo hay una muy ligera diferencia: en el extremo septentrional, siguiendo el gradiente pautado del conjunto regional, hay más plantas supra y extramediterráneas. Hacia el Sur, la tendencia es la contraria, presentándose una cesura evidente a partir de la cuadrícula central; de modo que en el sector centro-meridional de AM hay una mayor prevalencia relativa de las plantas mediterráneas amplias. Los valores extremos de $\mathrm{C} 4$ se explican por su menor riqueza florística y por la singularidad propiciada por un menor grado de antropización (comentado en García-Abad, 2011).

\subsection{ESPECTROS DE LA FLORA ALÓCTONA (FITODIVERSIDAD XENOFÍTICA)}

El análisis en AM de espectros de las plantas autóctonas (nativas, si se prefiere) ha sido analizado en García-Abad (2009 y 2011) y en el apartado anterior. El análisis de las plantas alóctonas (antropófitos, exóticas, foráneas, sinántropas o xenófitos, como se prefiera) será abordado a continuación.

La acción humana desde el Neolítico y, especialmente, desde la época de las grandes invasiones y formación de los grandes imperios durante la Edad Antigua, ha contribuido durante milenios a expandir la territorialidad de varios táxones lejos de sus centros de origen. Con el desarrollo del comercio y, definitivamente, con el descubrimiento y ocupación europeos de América y Australia, esta tendencia se acrecentó. No por capricho, se estableció como límite temporal normalizado el año 1500 para diferenciar en Europa las plantas alóctonas entre arqueófitos y neófitos (Pyšek et al., 2004; La Sorte et al., 2008). A su vez, América, Oceanía y bastantes archipiélagos comenzaron a recibir también plantas del resto de continentes. Esta realidad fitogeográfica cultural ha dado pie en las últimas décadas a numerosos estudios especiales ecológicos y biogeográficos sobre plantas alóctonas (Lodge, 1993; Rosenzweig, 2001; Sanz et al., 2004; Pauchard y Shea, 2006; Chytrý et al., 2008; Alexander y Edwards, 2010, entre muchísimos otros) e, igualmente, están comenzando a ser discriminadas en las floras y analizados sus espectros (Pyšek et al., 2004; Acedo y Llamas, 2007; Campos y Herrera, 2009; Aeschimann et al., 2011).

El tratamiento de este apartado tiene especial interés para el conjunto regional de AM, pues supone una aportación inédita. En un ANEXO, al final, se expone el listado de plantas alóctonas recopiladas en las fuentes más las avistadas en trabajos de campo propios. Este listado tiene, desde luego, un carácter provisional y está sujeto a adiciones y, en su caso, correcciones. Sin embargo, respecto a las cuadrículas de un transecto en el que se evitaron a propósito ambientes extremadamente humanizados (más propicios para la aloctonía), los datos recabados son representativos sólo de los espacios alcarreño-ocañenses con biótopos seminaturales y agrarios adosados dominantes, pero no del conjunto regional globalmente considerado. 
Una vez analizada la procedencia de las plantas, la Tabla 3 muestra el desglose numérico elemental entre plantas autóctonas y alóctonas (con híbridos). Y en la Figura 5 se reducen a porcentajes los datos de esa Tabla 3.

Tabla 3: Número de táxones (hasta rango de variedad) y nothotáxones vasculares, según autoctonía/aloctonía.

\begin{tabular}{|r|r|r|r|r|}
\hline Unidades y Transecto & Autóctonos & Alóctonos & Ratio & TOTAL \\
\hline C1: 30T WL 0624 & 462 & 18 & 25,7 & $\mathbf{4 8 0}$ \\
C2: 30T VK 9395 & 441 & 19 & 23,2 & $\mathbf{4 6 0}$ \\
C3: 30T VK 8264 & 416 & 18 & 23,1 & $\mathbf{4 3 4}$ \\
C4: 30T VK 7136 & 311 & 3 & 103,7 & $\mathbf{3 1 4}$ \\
C5: 30S VK 6207 & 402 & 21 & 19,1 & $\mathbf{4 2 3}$ \\
\hline $\mathbf{5 C}$ & $\mathbf{6 9 4}$ & $\mathbf{3 8}$ & $\mathbf{1 8 , 3}$ & $\mathbf{7 3 2}$ \\
\hline AM & $\mathbf{1 6 5 7}$ & $\mathbf{1 9 4}$ & $\mathbf{8 , 5}$ & $\mathbf{1 8 5 1}$ \\
\hline
\end{tabular}

Fuentes: AM, (García-Abad (2006 y 2009); resto, trabajo de campo (año 2002-03).

Figura 5. Distribución proporcional de plantas alóctonas y autóctonas

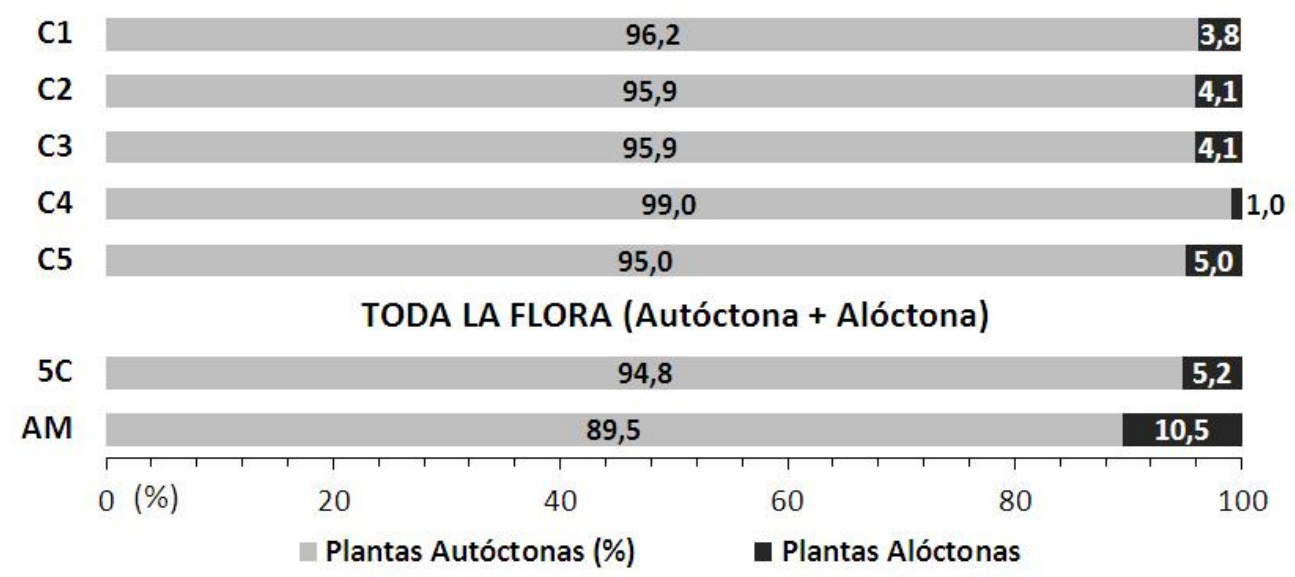

Fuentes: Elaboración propia, a partir de AM, (García-Abad (2006 y 2009); resto, trabajo de campo (año 2002-03).

En AM, el 10,5\% de plantas son alóctonas (hay 1 planta alóctona por cada 8,5 autóctonas). Sin embargo, las cuadrículas del transecto presentan niveles de aloctonía significativamente menores (1 por cada 18,3), con una proporción inferior a la mitad del conjunto regional, debido al argumento referido más arriba. Este modesto contingente xenofítico, sin embargo, se presenta como habitual y relativamente repetitivo en el "interior seminatural" alcarreño-ocañense muestreado que, estando menos expuesto 
a la proliferación de exotismos vegetales de otros sectores de AM, está sin embargo influido por una agricultura tradicional secular (milenaria, en las arterias fluviales más amplias): rosáceas frutícolas (destaca el género Prunus), leñosas de la típica tríada mediterránea (Olea y Vitis), nogales e higueras. Estos elementos se ven acompañados por neófitos herbáceos ampliamente generalizados por la actividad agrícola (bledos del género Amaranthus y los abrojos del género Xanthium, fundamentalmente). Entre ellos, otros destacan por su reciente introducción (Epilobium brachycarpum -oportunista también en biótopos urbanícolas-, Gypsophila pilosa y el tomatito de la reciente gastronomía de diseño Physalis sp., que suele encontrarse en las vegas cultivadas -sobre todo, de girasol-).

Pese a la fuerte excepción que supone C4 (Tabla 3), se aprecia un cierto gradiente geográfico de aumento hacia el Sur de la proporción de alóctonas respecto a autóctonas (Figura 5). Ya se comentó en García-Abad (2011) el bajo grado de antropizacíon florística de $\mathrm{C} 4$, pero sorprende más aún observar ahora cómo apenas fueron tres los xenófitos encontrados.

El espectro fitoecológico de la flora alóctona en estas cuadrículas pone de manifiesto, en definitiva, la mencionada pauta de cultivo agrícola y malas hierbas asociadas como la principal y dominante (Figura 6).

Figura 6. Espectro Fitoecológico de la Flora Alóctona (táxones y nothotaxones)

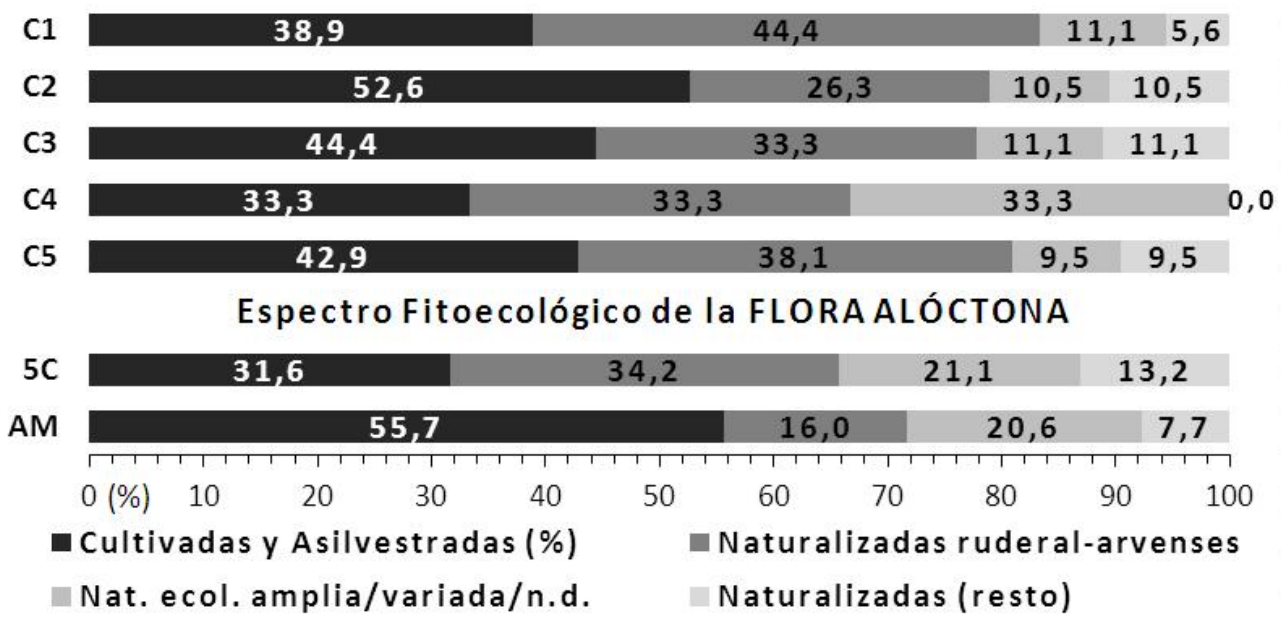

NOTA: Se aplica el método empleado en García-Abad (2011): a) Naturalizadas ruderal-arvenses ("Hrv", del trabajo referido), b) Naturalizadas de ecología amplia, variada o no determinada fitosociológicamente (“av"), y c) resto de clases fitosociológicas.

Fuentes: Elaboración propia, a partir de AM, (García-Abad (2006 y 2009); resto, trabajo de campo (año 2002-03). 
En esta pauta, en principio no se aprecia ninguna tendencia en el transecto que permita aventurar gradiente geográfico alguno. Si no fuera por la excepción de $\mathrm{C} 4$, podría pensarse incluso en ausencia del mismo; esto es, en cierta homogeneidad en la composición florística alóctona propia de áreas de cultivos agrícolas. Apoya esta idea el comprobar cómo el agregado cultivos-malas hierbas (Figura 6) se sitúa en torno al $80 \%$ (rango entre 77,7 y $83,4 \%$ ) en las cuatro cuadrículas restantes. Igualmente, concurre en la misma apoyatura el valor de $31,6 \%$ de plantas cultivadas en $5 \mathrm{C}$; es decir, un valor claramente menor que el de las cinco cuadrículas. Ello indica poca diversidad de las plantas cultivadas en los ámbitos geocológicos involucrados en el transecto del "interior" alcarreño-ocañense y suficientemente ajenos a los ambientes extramadamente humanizados de otras áreas de AM.

Sin embargo, en las visitas a las cinco cuadrículas se observó que la afección de xenófitos fue prácticamente nula en los concretos espacios seminaturales de bosques, monte bajo y matorrales no mésicos (la única excepción pudo ser la presencia muy esporádica de Medicago sativa). Y, en las olmedas y praderas meso-higrófilas, los observados fueron tan sólo Asperugo probumbens, Echinochloa crus-galli, Polypogon monspeliensis y Rubia tinctorum.

La Tabla 4 muestra el espectro taxonómico del contingente floral alóctono. Y la Figura 7 los porcentajes en las unidades territoriales.

En AM, las tres primeras familias que lideran en términos relativos la flora alóctona son las mismas que lideran la flora autóctona, con la diferencia de que las compuestas ocupan el tercer lugar, en vez del primero. Las dos primeras familias mantienen curiosamente unos porcentajes muy similares a los que poseían para la flora autóctona.

El espectro típico de la flora alóctona en AM es el siguiente:

$$
\text { Gram }>\text { Leg }>\text { Comp }>\text { Ros }>\text { Ama }>\text { Sol }>\text { Chen }>\mathrm{Cuc}^{2}
$$

Puede apreciarse cómo las rosáceas ocupan un lugar mucho más destacado respecto a la flora autóctona (árboles frutales habituales en las huertas y que, a veces, se asilvestran $^{3}$ ), y cómo en el Top8 de las foráneas aparecen tres familias que eran muy minoritarias entre las nativas: amarantáceas (los bledos ya referidos), solanáceas y cucurbitáceas (plantas hortícolas habituales que, aunque muy raramente, se asilvestran). Las gimnospermas (agrupadas en la Figura 7: pinos y cipreses de repoblaciones, ornamentación, sombra, barreras, etc) ocupan también un lugar relativamente más destacado respecto al espectro autóctono ${ }^{4}$.

\footnotetext{
${ }^{2}$ Estas ocho familias suponen casi el $46 \%$ de toda la flora autóctona.

${ }^{3}$ Caso aparte es el almendro (Prunus dulcis), poco exigente en humedad edáfica, que se implanta sobre todo en áreas no hortícolas, formando habitualmente setos entre cultivos de secano, olivares y viñas. Está muy extendido, se encuentra muy frecuentemente y se asilvestra con facilidad. Además del importante aporte nutritivo de sus frutos secos, entre otros usos, su madera se ha empleado bastante como leña.

${ }^{4}$ Cotéjense todos estos datos con los correspondientes expuestos en García-Abad (2009).
} 
Tabla 4. Número de plantas alóctonas por grupos taxonómicos (con híbridos)

\begin{tabular}{|c|c|c|c|c|c|c|c|}
\hline GRUPOS & $\mathbf{A M}$ & $5 C$ & C1 & $\mathrm{C} 2$ & C3 & $\mathrm{C4}$ & C5 \\
\hline Gymnospermae & $7(2)$ & & & & & & \\
\hline Dicotiledones & $\begin{array}{l}159 \\
(59)\end{array}$ & $\begin{array}{c}29 \\
(18)\end{array}$ & $\begin{array}{c}15 \\
(11)\end{array}$ & $\begin{array}{c}18 \\
(14)\end{array}$ & $\begin{array}{c}15 \\
(13)\end{array}$ & $\begin{array}{c}3 \\
\text { (3) }\end{array}$ & $\begin{array}{c}19 \\
(11)\end{array}$ \\
\hline Leguminosae & 16 & 1 & 1 & 1 & 1 & & 1 \\
\hline Compositae & 14 & 6 & 3 & 1 & 2 & & 4 \\
\hline Rosaceae & 13 & 7 & 2 & 5 & 2 & & 4 \\
\hline Amaranthaceae & 8 & 3 & 2 & 1 & 1 & & 3 \\
\hline Solanaceae & 7 & 1 & & 1 & & & \\
\hline Chenopodiaceae & 6 & & & & & & \\
\hline Cucurbitaceae & 6 & & & & & & \\
\hline Oleaceae & 5 & 1 & 1 & 1 & 1 & 1 & 1 \\
\hline Cruciferae & 5 & 1 & & 1 & 1 & & \\
\hline Resto de Familias & 79 & 12 & 6 & 7 & 7 & 2 & 6 \\
\hline Monocotiledones & $\begin{array}{l}28 \\
(5)\end{array}$ & $\begin{array}{c}6 \\
(2)\end{array}$ & $\begin{array}{c}3 \\
\text { (1) }\end{array}$ & $\begin{array}{c}1 \\
(1)\end{array}$ & $\begin{array}{c}3 \\
\text { (2) }\end{array}$ & & $\begin{array}{c}3 \\
(2)\end{array}$ \\
\hline Gramineae & 19 & 4 & 3 & & 2 & & 1 \\
\hline Liliaceae & 5 & 2 & & 1 & 1 & & 2 \\
\hline Resto de Familias & 4 & & & & & & \\
\hline Hasta Familia & 66 & 20 & 12 & 15 & 15 & 3 & 13 \\
\hline H. Género & 146 & 32 & 15 & 18 & 18 & 3 & 18 \\
\hline H. Esp/Sub/Var & 194 & 38 & 18 & 19 & 18 & 3 & 22 \\
\hline
\end{tabular}

* Entre paréntesis aparece el número de familias.

Fuentes: Elaboración propia, a partir de AM, (García-Abad (2006 y 2009); resto, trabajo de campo (año 2002-03).

Los géneros con mayor número de plantas alóctonas en AM son, por orden decreciente los siguientes: Amaranthus (8 especies), Prunus (7), Acer (4), Xanthium (4), Cucumis (3), Pinus (3), Veronica (3) y Vicia (3).

En cuanto al transecto de las cinco cuadrículas, al ser bajo el número de plantas involucradas en términos absolutos y relativos (según se señaló más arriba), no se observa ajuste claro con el modelo regional, con la única excepción de que el porcentaje en gramíneas es bastante similar (10,5\% en 5C). Destaca, en todo caso, el pico proporcionalmente alto que presentan las rosáceas $(18,4 \%)$, las compuestas $(15,8 \%)$ y amarantáceas $(7,9 \%)$. Además, C2 sobresale por albergar bastantes rosáceas alóctonas (el $38,5 \%$ de todas las referenciadas en AM). Este dato puntual se extiende al transecto: el 53,8\% de estas rosáceas alóctonas alcarreño-ocañenses han sido encontradas en $5 \mathrm{C}$, como resultado de la pauta agrícola reseñada. 
Figura 7. Espectro Taxonómico de La Alcarria y Mesa de Ocaña (con híbridos)

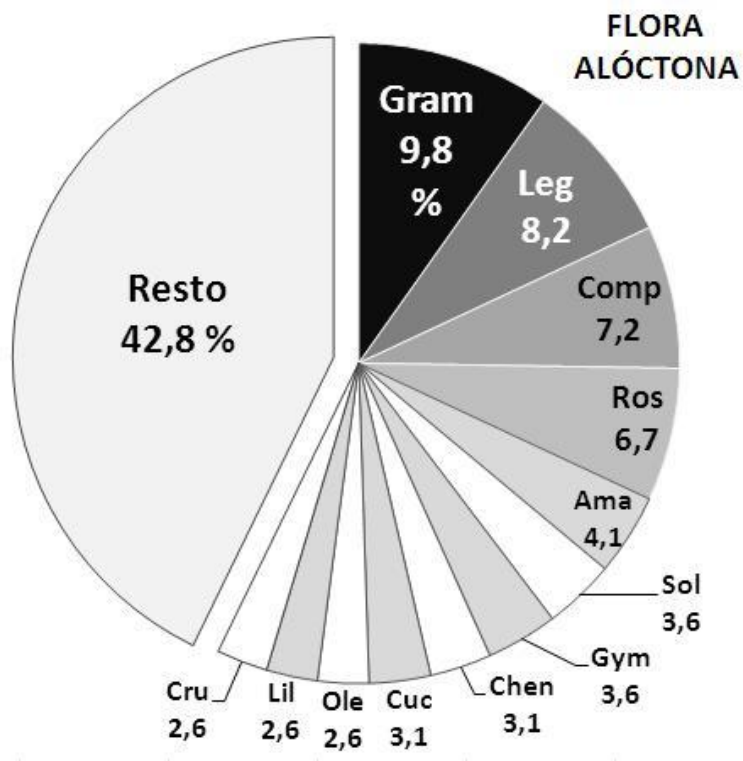

Fuentes: Elaboración propia, a partir de AM, (García-Abad (2006 y 2009); resto, trabajo de campo (año 2002-03).

El análisis de semejanza florística entre la flora alóctona, según el índice de Jaccard (análogo al efectuado en García-Abad, 2009), revela que las dos parejas de cuadrículas más similares son $\mathrm{C} 1 \mathrm{C} 3(\gamma=0,55)$ y $\mathrm{C} 2 \mathrm{C} 3(\gamma=0,48)$, estando el resto de emparejamientos ya bastante alejados $(\gamma<0,39)$. C3 es el recinto que presenta mayor semejanza media, como cabía esperar por encontrarse en el centro geográfico del transecto. Sólo dos xenófitos son comunes a las cinco cuadrículas: Olea europaea y Veronica polita. Evidentemente, la anomalía de $\mathrm{C} 4$ es la causante de tan reducida cifra. Si no consideramos esta cuadrícula, se unirían otras cinco más como plantas alóctonas comunes, pues se encuentran en las otras cuatro cuadrículas (Amaranthus blitoides, Ficus carica, Medicago sativa, Prunus dulcis y Vitis vinifera). Y son cuatro las que se presentan en tres cuadrículas (Epilobium brachycarpum, Juglans regia, Malus domestica y Xanthium spinosum). 
El espectro biotípico de la flora alóctona difiere bastante del de la flora autóctona. Los datos de la Tabla 5 y la reducción simplificada ${ }^{5}$ de $\operatorname{los}$ mismos efectuada en la Figura 8 lo pone claramente de manifiesto.

Tabla 5. Número de plantas alóctonas por biótipos ${ }^{1}$ (con híbridos)

\begin{tabular}{|r|c|c|ccccc|}
\hline BIÓTIPOS $^{\mathbf{6}}$ & AM & 5C & C1 & C2 & C3 & C4 & C5 \\
\hline T & 66 & 18 & 10 & 7 & 9 & 1 & 9 \\
\hline Mif & 28 & 7 & 2 & 4 & 3 & & 6 \\
\hline H & 19 & 3 & 1 & 1 & 1 & & 3 \\
\hline Mif-Nf & 11 & 3 & 2 & 3 & 2 & 1 & 2 \\
\hline Maf-Msf & 10 & 2 & 2 & 1 & 1 & & \\
\hline G & 9 & 2 & & 1 & 1 & & 2 \\
\hline Msf & 9 & & & & & & \\
\hline H-T & 8 & 1 & & & & 1 & \\
\hline C & 7 & & & & & & \\
\hline Nf & 6 & & & & & & \\
\hline Mif-Msf & 5 & 2 & 1 & 2 & 1 & & \\
\hline C-H & 3 & & & & & & \\
\hline Maf & 3 & & & & & \\
\hline L & 2 & & & & & \\
\hline Otros & 8 & & & & & \\
\hline
\end{tabular}

Fuentes: Elaboración propia, a partir de AM, (García-Abad (2006 y 2009); resto, trabajo de campo (año 2002-03).

Aunque los terófitos, biótipo líder de la flora autóctona, mantienen un porcentaje similar, en el caso de la flora alóctona son relegados por muy poco por el liderazgo de los fanerófitos (Figura 8). Tan sólo los geófitos, además de terófitos, mantienen proporciones similares.

\footnotetext{
${ }^{5}$ La simplificación consiste en contabilizar el $50 \%$ de las plantas ambivalentes (con guión) para cada uno de los dos componentes, teniendo en cuenta que Nf, Maf, Mif y Msf se agrupan como F (Fanerófitos). Ver lo correspondiente en García-Abad (2011).

${ }^{6}{ }^{1}$ Biótipos según Rivas-Martínez et al. (2007). ${ }^{2}$ Abreviaturas: C, Caméfitos; G, Geófitos; H, Hemicriptófitos; L, Lianas; Maf, Macrofanerófitos; Mif, Microfanerófitos; Msf, Mesofanerófitos; Nf, Nanofanerófitos y T, Terófitos. Las abreviaturas separadas por guión significa que se trata de plantas que pueden presentarse con ambos biótipos, o bien que poseen caracteres intermedios entre ellos. Ver lo correspondiente en García-Abad (2011)
} 
Efectivamente, son arbolillos y árboles introducidos por el hombre de manera premeditada, fundamentalmente para uso ornamental y de cultivo agrícola, los que provocan este importante vuelco. En todo caso, entre las alóctonas que llegaron a La Alcarria Occidental y Mesa de Ocaña de manera fortuita o no premeditada (naturalizadas, en líneas generales), el biótipo más importante es con diferencia el de los terófitos. Ese notable aumento de fanerófitos alóctonos va en detrimento de hemicriptófitos (sobre todo en los de carácter cultivado/asilvestrado) y caméfitos alóctonos, biótipos que ven bastante mermada su proporción en el conjunto floral respecto a los autóctonos.

La Tabla 6 muestra el espectro biogeográfico del contingente floral alóctono. Y la Figura 9 muestra reducidos sus datos en porcentajes.

Figura 8. Espectro Biotípico de La Alcarria y Mesa de Ocaña (con híbridos)

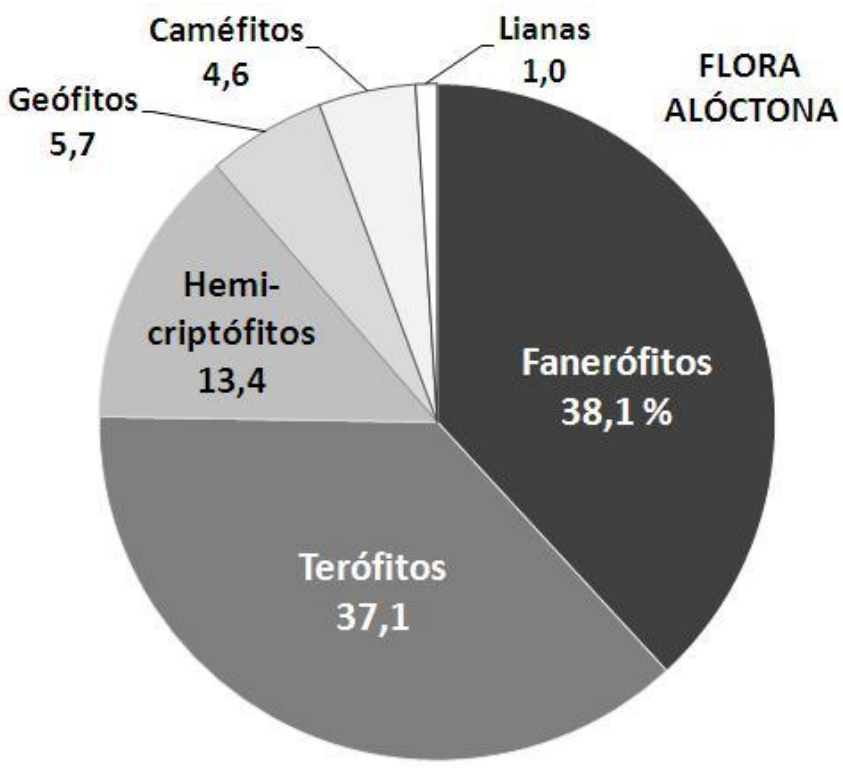

Fuentes: Elaboración propia, a partir de AM, (García-Abad (2006 y 2009); resto, trabajo de campo (año 2002-03).

El centro de origen de las plantas alóctonas referenciadas en AM está bastante repartido, sin que sea especialmente dominante ninguno de ellos. Está liderado por la agrupación de elementos tropicales estrictos (Cucurbita, Physalis, Setaria, entre otros géneros), destacando sobre todo los neotropicales. Le siguen elementos estenomediterráneos entre los que destacan por su gran frecuencia la alfalfa silvestre (Medicago sativa) y el olivo, además de la higuera y el ciprés de los cementarios, entre otros. Éstos, junto a las plantas eurimediterráneas (vid, zumaque, almez, árbol del amor, etc), 
constituirían un grupo mediterráneo amplio que casi supondría el $20 \%$ de todos los xenófitos.

Importante es el grupo de plantas perieuropeas de los ámbitos áridos y muy áridos de sur (Sáhara) y del SE (arco irano-turaniano): centaureas arvenses, cereales agrícolas, granado y membrillero, entre otros. Destaca también las plantas de origen americano no estrictamente tropical (14\% de las alóctonas). De este origen son, precisamente los bledos y otros congéneres del género Amaranthus, así como los abrojos del género Xanthium.

Tabla 6. $\mathrm{N}^{\mathrm{o}}$ de plantas alóctonas por tipos de distribución geográfica (con híbridos)

\begin{tabular}{|l|c|c|ccccc|}
\hline DISTRIBUCIÓN GEOGRÁFICA & AM & 5C & C1 & C2 & C3 & C4 & C5 \\
\hline Estenomediterránea Oriental & 8 & 3 & 1 & 1 & 2 & & 3 \\
\hline Estenomediterránea Occidental y SW & 5 & & & & & \\
\hline Estenomediterránea & 8 & 3 & 2 & 2 & 2 & 1 & 3 \\
\hline Eurimediterránea & 17 & 2 & 1 & 1 & 1 & 1 & 1 \\
\hline Europea & 9 & 1 & & 1 & & & \\
\hline Eurosiberiana y/o Boreal & 8 & 1 & & 1 & 1 & \\
\hline Irano-Turaniana / Sahariana (y Euri-) & 18 & 7 & 2 & 5 & 4 & 1 & 3 \\
\hline Europea/Eurieuropea/Perieuropea & $\mathbf{7 3}$ & $\mathbf{1 7}$ & $\mathbf{6}$ & $\mathbf{1 1}$ & $\mathbf{1 0}$ & $\mathbf{3}$ & $\mathbf{1 0}$ \\
\hline Euroasiática (y Euri-) & 14 & 4 & 3 & 2 & 1 & & 1 \\
\hline Centroasiática & 6 & & & & & \\
\hline Asiática (no chinojaponesa) & 11 & 2 & & & & \\
\hline Africana y Afro-Asiática & 4 & & & & & \\
\hline Holoártica & 2 & 1 & & 1 & & \\
\hline Ampliamente Supraeuropea & $\mathbf{3 7}$ & $\mathbf{7}$ & $\mathbf{3}$ & $\mathbf{3}$ & $\mathbf{1}$ & $\mathbf{4}$ \\
\hline Chinojaponesa & 12 & 1 & & 1 & 1 & \\
\hline Norteamericana & 18 & 5 & 4 & 1 & 3 & & 3 \\
\hline Paleotropical & 6 & 3 & 3 & & 1 & 1 \\
\hline Neotropical & 22 & 2 & & 1 & & 1 \\
\hline Sudamericana & 5 & 1 & 1 & 1 & & 1 \\
\hline Americana (ambos subcontinentes) & 4 & 1 & 1 & & 1 & 1 \\
\hline Australiana y Capense & 2 & & & & & \\
\hline Ampliamente Extraeuropea & $\mathbf{6 9}$ & $\mathbf{1 3}$ & $\mathbf{9}$ & $\mathbf{4}$ & $\mathbf{6}$ & $\mathbf{7}$ \\
\hline Desconocida o Incierta & $\mathbf{1 5}$ & $\mathbf{1}$ & & $\mathbf{1}$ & $\mathbf{1}$ & $\mathbf{1}$ \\
\hline TOTAL ALÓCTONAS & $\mathbf{1 9 4}$ & $\mathbf{3 8}$ & $\mathbf{1 8}$ & $\mathbf{1 9}$ & $\mathbf{1 8}$ & $\mathbf{3}$ & $\mathbf{2 2}$ \\
\hline
\end{tabular}

Fuentes: Elaboración propia, a partir de AM, (García-Abad (2006 y 2009); resto, trabajo de campo (año 2002-03). 
Los elementos euroasiáticos amplios suponen en torno al 30\%: casi todas las rosáceas frutícolas, arces y quenopodiáceas del género Atriplex son los más numerosos. Pero se trata de una agrupación especialmente amplia en la que existen importantes y muy diferentes matices geográficos. Sobresale al respecto el centro de origen chinojaponés, de donde proviene el ailanto, árbol muy habitual en las cunetas de las carreteras, donde se asilvestra con muchísima facilidad. Otros elementos son ornamentales (Euonymus japonicus, Koelreuteria paniculata, Ligustrum lucidum, Lonicera japoni$c a$, etc). Elementos sobresalientes de otros centros euroasiáticos serían, por citar algún ejemplo: el nogal y el chopo negro (arqueófitos euroasiáticos), el lilo y el peral (europeos) o el pino silvestre (eurosiberiano) que, siendo autóctono en la Península Ibérica, no lo es en AM en el Holoceno reciente.

Figura 9. Espectro Biogeográfico de La Alcarria y Mesa de Ocaña (con híbridos)

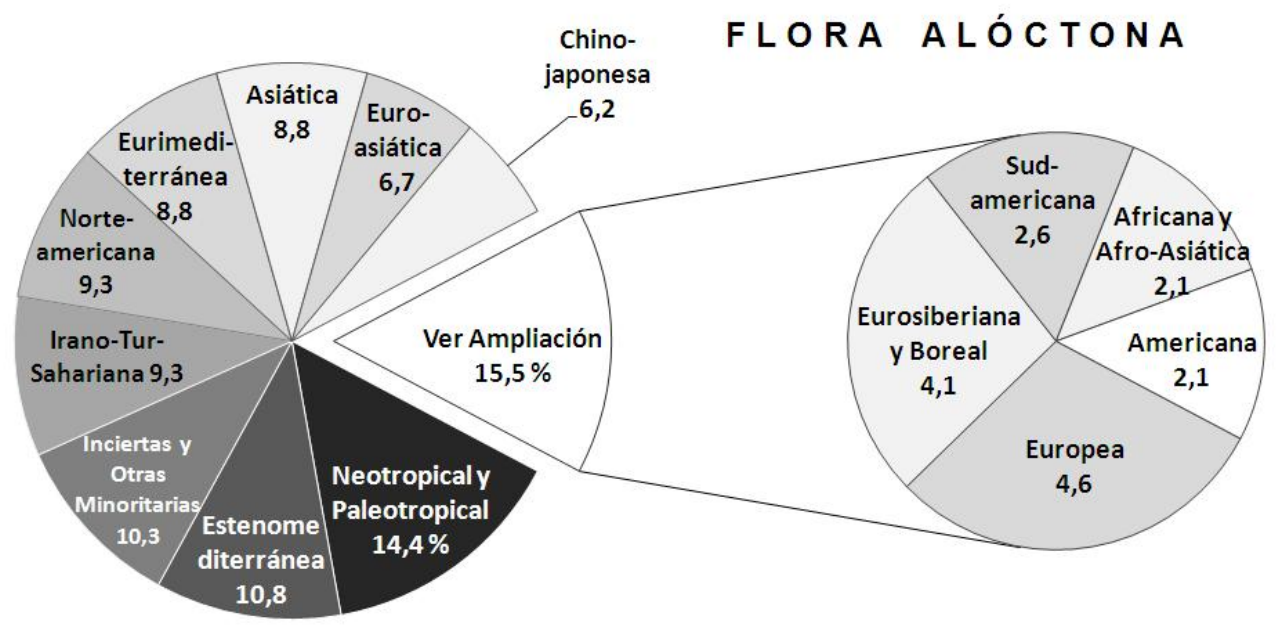

Fuentes: Elaboración propia, a partir de AM, (García-Abad (2006 y 2009); resto, trabajo de campo (año 2002-03).

En cuanto a las cuadrículas del transecto (no especialmente representativas del conjunto regional, como ya se ha dicho), lo más reseñable es que cuantitativamente: a) el único ajuste respecto al modelo regional se presenta en las plantas de origen tropical estricto $(13,2 \%$ en $5 \mathrm{C})$; y b) destacan especialmente por encima de la proporción regional las plantas de origen irano-turaniano (18,4\% en 5C).

Por orden decreciente, los cuatro elementos principales son: las referidas iranoturanianas (almendro y Veronica polita, sobre todo), las estenomediterráneas (olivo, higuera y alfalfa silvestre están siempre o casi siempre), las tropicales estrictas (destacan las paleotropicales Polypogon monspeliensis y Setaria viridis) y las norteamericanas (Amaranthus blitoides, A.retroflexus, Conyza canadensis y Xanthium orientale son las más habituales). 


\subsection{CARÁCTER INVASOR/NO INVASOR DE LA FLORA ALÓCTONA (FITODIVERSIDAD XENOFÍTICA)}

Además de este cuadro general sobre las plantas de procedencia foránea, ha tomado fuerza en las últimas décadas el apartado de alóctonas a las que se añade un carácter invasor; es decir, fitoelementos no nativos que, además de implantarse en tierras ajenas, compromenten o pueden comprometer negativamente la estabilidad poblacional y ecológica de algunas especies autóctonas, llegando a desplazarlas de sus hábitat naturales y/o a mermar seriamente su existencia (Daehler, 1998; Kolar y Lodge, 2001; McNeely, 2001; Sanz et al., 2004; Campos y Herrera, 2009). Este concepto de "invasora" sería sinónimo, pues, de implantación dañina o no deseada, y que requiere de una gestión y de medidas activas para anular o mitigar sus efectos (Sanz et al., 2004, Larson et al., 2011). En España, el trabajo efectuado por Sanz et al. (2004) ha puesto de relieve esta cuestión, pues junto al catálogo de las plantas alóctonas, presenta fichas específicas de aquellas que poseen ese sentido ambientalmente pernicioso. Así pues, la Tabla 7 presenta el cuadro xenofítico en las unidades estudiadas. Y en la Figura 10 los datos se reducen a porcentajes.

Tabla 7. Número de plantas alóctonas invasoras y no invasoras, y ratios

\begin{tabular}{|r|r|r|r|r|}
\hline $\begin{array}{c}\text { Unidades y Transec- } \\
\text { to }\end{array}$ & $\begin{array}{c}\text { Alóct. } \\
\text { Inv. (1) }\end{array}$ & $\begin{array}{c}\text { Alóct. } \\
\text { No Inv. (2) }\end{array}$ & $\begin{array}{c}\text { Ratio } \\
\text { (3) }\end{array}$ & $\begin{array}{c}\text { Ratio } \\
(4)\end{array}$ \\
\hline C1: 30T WL 0624 & 4 & 14 & 3,50 & 117,25 \\
C2: 30T VK 9395 & 3 & 16 & 5,33 & 150,33 \\
C3: 30T VK 8264 & 3 & 15 & 5,00 & 143,33 \\
C4: 30T VK 7136 & 0 & 3 & no & no \\
C5: 30S VK 6207 & 5 & 16 & 3,20 & 83,00 \\
\hline $\mathbf{5 C}$ & $\mathbf{7}$ & $\mathbf{3 1}$ & 4,43 & 102,43 \\
\hline $\mathbf{A M}$ & $\mathbf{3 1}$ & $\mathbf{1 6 3}$ & $\mathbf{5 , 2 6}$ & $\mathbf{5 7 , 8 4}$ \\
\hline
\end{tabular}

Fuentes: Elaboración propia, a partir de AM, (García-Abad (2006 y 2009); resto, trabajo de campo (año 2002-03).

${ }^{7}$ (1) Según adscripción de Sanz et al. (2004) para la Península Ibérica. (2) Plantas alóctonas no adscritas al grupo anterior. (3) Número de alóctonas no invasoras por cada alóctona invasora. (4) Número de alóctonas invasoras por cada espontánea no invasora (1793, en AM; 717, en 5C; 469, en C1; 451, en C2; 430, en C3; 314, en C4; y 415, en C5). 
Figura 10. Espectro Invasor de la Flora Alóctona (táxones y nothotaxones)

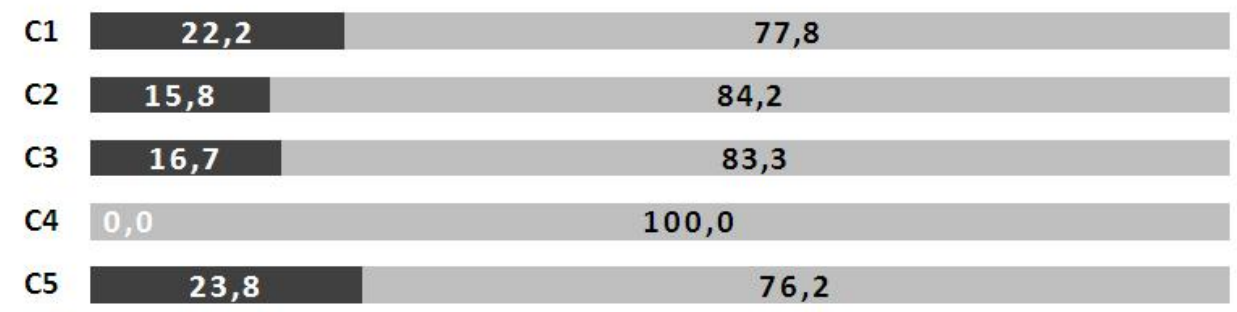

Espectro Invasor de Ia FLORA ALÓCTONA

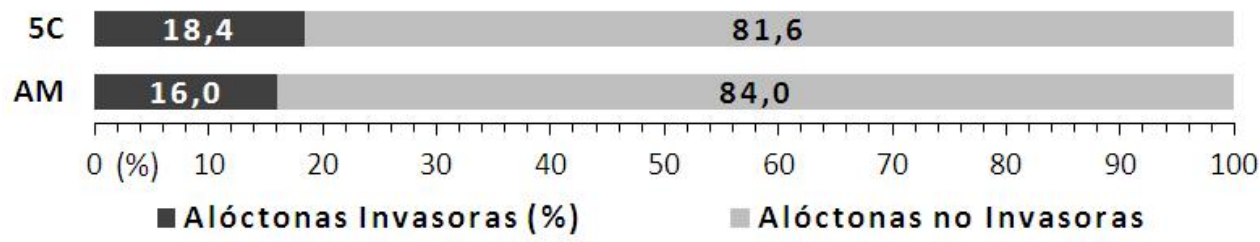

Fuentes: Elaboración propia, a partir de AM, (García-Abad (2006 y 2009); resto, trabajo de campo (año 2002-03).

En AM, por cada planta alóctona invasora referenciada hasta ahora hay algo más de cinco que no lo son. Esta proporción es un poco más baja en el conjunto del transecto efectuado, aunque prácticamente se mantiene en las dos cuadrículas intermedias madrileño-guadalajareñas $(\mathrm{C} 2$ y C3). Pero, si estas proporciones se calculan respecto a todas las plantas espontáneas, la proporción asciende en AM a casi sesenta plantas espontáneas no invasoras por cada invasora. Se observa, en este caso, sin embargo que el transecto posee un nivel de antropización bastante menor que el pautado en AM (pues la ratio alcanza casi el doble), siendo esas mismas cuadrículas intermedias las menos afectadas. De ello puede deducirse en principio que, aun habiendo pocas plantas alóctonas, las invasoras son de las primeras en implantarse en esos ámbitos seminaturales y agrarios asociados.

Y la razón básica y generalizada es que en AM las invasoras se expanden fundamentalmetne por el cultivo agrícola. Esto se pone claramente de manifiesto observando cómo son los tres bledos (Amaranthus spp.), las dos conizas (Conyza spp.) y el abrojo (Xanthium spinosum), es decir arvenses de primera fila, las habituales y casi únicas invasoras en las cinco cuadrículas.

En términos relativos, el 16\% de las plantas alóctonas en AM son invasoras. Pese a que en el transecto $5 \mathrm{C}$ el porcentaje de alóctonas es más o menos la mitad que en AM, esa proporción de invasoras dentro del contingente alóctono curiosamente se mantiene bastante similar al regional (es un poco mayor: $18,4 \%$ ). Pero lo hace de manera desigual, pues las cuadrículas de los extremos septentrional y meridional presentan un porcentaje mayor (22-24\%) suficientemente decantado. 


\section{DISCUSIÓN Y CONCLUSIONES}

Se ha visto que en AM las plantas geográficamente más estenoicas son muy pocas, lo que revela el paupérrimo potencial ecogeográfico como refugio de especiación que posee esta región natural: tres de esos táxones son del género Limonium, muy proclive a la microendemicidad (Vol. 3, 1993, de Castroviejo, 1986-2008); y los otros dos sólo tienen rango subespecífico. Téngase en cuenta, al respecto, lo extremadamente alejadas que se encuentran las cifras de esta pequeña región centro-peninsular, cuando se compara por ejemplo con la gran endemicidad que genera el sur peninsular: 545 endemismos (más del 15\%) en un territorio que abarca Andalucía, Murcia y el Algarve portugués (Melendo et al., 2003).

A otro nivel, los valores de endemicidad ibérico-balear de AM no son especialmente destacados, aunque tampoco pueden considerarse bajos en relación con su superficie $\left(6.700 \mathrm{~km}^{2}\right)$. De los datos obtenidos se deduce que la situación centropeninsular de AM permite una tasa de endemicidad de ligera relevancia a escala de táxones ampliamente peninsulares. Todo ello es atribuible a que, siendo una región florística de transición, recibe influencias tangenciales de focos peninsulares más destacados a este respecto (sobre todo, Cordillera Ibérica y, ya menos, las Béticas), así como a la especificidad más directa por adaptación ecofisiológica que impone la presencia de yesos -gipsofilia- (Mota et al., 2011) en la Depresión del Tajo.

En todo caso y dentro de este contexto, las cuadrículas seleccionadas por sí solas mantienen la pauta de albergar un número alto de plantas endémicas ibérico-baleares. Esta constatación se pone de manifiesto por los resultados obtenidos en un estudio geográfico-florístico de detalle efectuado en un sector septentrional de $\mathrm{AM}^{8}$ (GarcíaAbad et al., 2009). En él, los valores más altos que se detectaron por kilómetro cuadrado oscilaban entre 20 y 29 endemismos; esto es, el rango en que precisamente se mueven las cuadrículas analizadas.

En relación con su superficie, AM tiene un número relativamente bajo de plantas alóctonas en el concierto ibérico-balear, pues no tiene ámbitos geográficos especialmente expuestos a la recepción y permanencia de exotismos vegetales (costas, climas con inviernos suaves, mediterraneidad no continentalizada, "subtropicalidad") ${ }^{9}$. En todo caso, la dilatada historia agraria de AM, unida a la presencia de los extrarradios

\footnotetext{
${ }^{8}$ El recinto $\mathrm{C} 1$ aquí estudiado también formó parte de ese trabajo.

${ }^{9}$ Para hacer una comparación algo ajustada de AM con otros territorios peninsulares, convendría restar las plantas exclusivamente cultivadas que se han referenciado, resultando una cifra de 167 plantas alóctonas espontáneas. Asturias, con unos $10.600 \mathrm{~km}^{2}$, tiene 572 alóctonas espontáneas; el País Vasco, con unos 7.200 km², tiene 478; Galicia, con unos $29.600 \mathrm{~km}^{2}$, tiene 328; Baleares, con unos $5.000 \mathrm{~km}^{2}$, tiene 304 (según Campos y Herrera, 2009). Cataluña, con unos $32.100 \mathrm{~km}^{2}$, tiene 109 neófitos (según Chytrý et al., 2008); es decir, algo más de lo que estimamos para AM (sin más precisión posible por el momento).
} 
de Madrid, del centro palatino de Aranjuez (con sus jardines y huertas aledañas "amplificadas" por la llanura aluvial del río Tajo) y del corredor industrial del Henares (Torrejón de Ardoz, Alcalá de Henares y Guadalajara) ha propiciado histórica y recientemente la entrada de elementos vegetales foráneos. En las últimas décadas, además, la ampliación y acomodación de las redes e infraestructuras de transporte viario, junto con la generalización de urbanizaciones de segunda residencia han supuesto también factores coadyuvantes a tales efectos. En suma, todo ello ha permitido que en AM un 9,2\% de la flora espontánea sea alóctona, lo que se aproximaría bastante al $10,7 \%$ de la Península y Baleares ${ }^{10}$; aunque esté bastante lejos de la horquilla 13,5-22\% que presentan otros territorios ibéricos (Asturias, Baleares, Galicia y País Vasco), según Campos y Herrera (2009).

La afección de xenófitos es abrumadoramente mayoritaria en los ambientes arvenses y ruderales, de modo que AM mantiene la pauta normal en Europa y en España de una introducción mayoritaria de plantas foráneas por razón de la agricultura y por la extensión de los cultivos en el territorio (Chytrý et al., 2008; Sanz et al., 2004). Entre otras observaciones, el análisis de semejanza florística confirma este hecho, pues seis de los once taxones alóctonos más comunes del transecto son plantas introducidas directamente por cultivo.

De todas formas, estimamos que la cifra de xenófitos aquí presentada probablemente se eleve bastante, si se continúa la prospección detallada del territorio en el futuro. Al respecto, Hulme (2008) pone de manifiesto la importancia de cuidar la contabilidad de xenófitos y, por tanto, de precisar más las ratios resultantes entre plantas nativas y no nativas. Además, ese número se elevaría sobre todo, si las áreas residenciales (ámbitos urbanos, jardines, centros históricos, urbanizaciones, centros recreativos y de ocio, etc) se pudieran visitar de manera sistemática (La Sorte et al., 2008 contemplan floras urbanas para valorar la diversidad) y sin restricciones de acceso; así como las áreas de servicio de las principales y más recientes vías de comunicación.

Aunque la cuadrícula villarrubiera (C4) rompe muy abruptamente la pauta y el gradiente geográfico mostrados en el transecto $5 \mathrm{C}$ en cuanto al porcentaje de alóctonas (y, en consecuencia, la ratio autóctonas/alóctonas), no resta interés el constatar que pueden encontrarse en AM algunos focos seminaturales muy poco afectados por plantas introducidas, pese a que incluyan espacios agrícolas adosados, como es el caso.

El paisaje vegetal que muestran las cuadrículas del transecto incluye plantas alóctonas cultivadas poco diversificadas. Los datos permiten interpretar, en principio, que

\footnotetext{
${ }^{10}$ Estos cálculos se han efectuado considerando 167 alóctonas espontáneas de un total de 1824 espontáneas (para AM: táxones + nothotáxones), y las 801 equivalentes (según Sanz et al., 2004) de un total de 7500 táxones (para Península y Baleares). En todo caso, debe advertirse que estos porcentajes son difíciles de precisar por la provisionalidad de los cómputos en ambas unidades territoriales.
} 
el agricultor transgredió históricamente, aunque fuera en ligera medida, algunos de los matices geoecológicos naturales de AM a la hora de elegir los recursos agrícolas. Evidentemente, las necesidades básicas de aceite, vino, cereales, frutos dulces y secos, junto con un sistema cultural uniforme para afrontar los aprovechamientos; sin olvidar las penurias, estrecheces, dificultades de comunicación y transporte propios de décadas y siglos pasados, entre otros aspectos, explican esta pauta geográfica.

Dentro del conjunto floral alóctono, en AM es poco numeroso el grupo de plantas consideradas invasoras en la Península Ibérica: el $16 \%$ (1,7\%, de toda la flora). El transecto analizado muestra que este fitoelemento no deseado ha afectado poco al ámbito regional de biótopos seminaturales y agrarios tradicionales (valores promedio inferiores al $1 \%$ en las cuadrículas, incluso nulos en una de ellas).

Según datos (provisionales por el momento) que hemos recabado en la última década, de las diez plantas invasoras que más frecuentemente aparecen en AM, siete de ellas son malas hierbas terofíticas introducidas por el trasiego de semillas en labores agrícolas (cuatro del género Amaranthus ${ }^{11}$ ), por la transhumancia ovina (Xanthium spinosum), comercio de la lana (Conyza bonariensis), o por razones fortuitas o no constatadas (Conyza canadensis); pero expandidas fundamentamente por la agricultura. Precisamente, seis de ellas aparecen en el transecto 5C, lo que avala nuevamente su representatividad. Las otras tres (Ailanthus altissima, Arundo donax y Robinia pseudoacacia), una de las cuales aparece en 5C, consisten en fanerófitos introducidos con fines ornamentales y otros usos (protección de cunetas y fijación de terrenos, barreras, cortavientos, material de construcción) ${ }^{12}$.

La determinación cuantitativa de plantas alóctonas en AM tiene el valor de haberse efectuado sobre una región que, al menos desde el punto de vista físico-natural, posee relativa homogeneidad. Ciertamente, no ocurre lo mismo desde el punto de vista histórico y humano, pues existe en ella bastante heterogeneidad en los grados de antropización (diversos procesos de ocupación y asentamiento en el territorio, usos del suelo, administraciones político-administrativas y otras transformaciones antropogénicas, tanto en la actualidad como históricamente). Algunos de ellos se han puesto de manifiesto en el transecto efectuado e, igualmente, se ha detectado un desajuste general entre los niveles de aloctonía regional respecto a los de su "interior" (5C).

${ }^{11}$ El caso de estos bledos (Amaranthus albus, A. blitoides, A. hybridus, A. retroflexus), considerados como pseudocereales por poseer granos parecidos a los de cereales cultivados, es paradigmático. De fenología estival, es común encontrarlos en los rastrojos y campos de cultivo de cereales y girasol, viñas (sobre todo las que se riegan) y, ya menos, en olivares y otros tipos de aprovechamiento agrícola.

${ }^{12}$ De los 10 xenófitos más frecuentes en AM, Conyza canadensis es probablemente uno de los más extendidos en Europa, pues también están presentes en Cataluña, Gran Bretaña y República Checa, según el reciente estudio de Chytrý et al. (2008). De aquéllos, 8 se encuentran en Cataluña como neófitos (op. cit.). 
Los resultados obtenidos en el conjunto de los cuatro trabajos (García-Abad, 2006, 2009, 2011 y el presente), así como los listados florísticos expuestos permiten contar con una base fundamental útil para informar futuros estudios que se efectúen en AM sobre composición y riqueza florísticas, distribuciones, pautas y niveles de antropización del paisaje y predicciones. Además, aquéllos constituyen datos que se unen a otros de diverso carácter útiles también para interpretar la configuración geohistórica del territorio.

\section{REFERENCIAS BIBLIOGRÁFICAS}

ACEDO, C. y LLAMAS, F. (2007): Catálogo de plantas alóctonas en la provincia de León (NW España). Studia Botanica, 25, 63-96.

AESCHIMANN, D., RASALOFO, N. y THEURILLAT, J.-P. (2011): Analyse de la flore des Alpes. 2: biodiversité et chorologie. Candollea, 66, 225-253.

AGUILELLA, A. y MATEO, G. (1998): Análisis biogeográfico cuantitativo de la pteridoflora de la provincia de Castellón. Flora Montiberica, 10, 31-48.

ALCARAZ, F. (2012): Biogeografía (Geobotánica, Tema 4). Versión de 5 de febrero de 2012. Licencia Creative Commons.

http://www.um.es/docencia/geobotanica/ficheros/tema04.pdf. [Consultado en junio de 2012].

ALEXANDER, J.M. y EDWARDS, P.J. (2010): Limits to the niche and range margins of alien species. Oikos, 119, 1377-1386.

BARTOLOMÉ, C., REJOS, F.J. y ÁLVAREZ, J. (2002): Flora y vegetación de la Baja Alcarria de Guadalajara. Unión Fenosa.

BOLOS, O. DE (1986): Consideracions sobre la flora del Montseny. Memorias de la Real Academia de Ciencias y Artes de Barcelona, Vol. XLVI (Núm, 16), 411-439.

BOLÒS, O. De y VIGO, J. (1984-2001): Flora dels Països Catalans. Barcelona. Barcino. 4 Vols.

CAMPOS, J.A. y HERRERA, M. (2009): Diagnosis de la flora alóctona invasora de la Comunidad Autónoma del País Vasco. Bilbao. Gobierno Vasco.

CASTROVIEJO, S. -Coord. Gral.- (1986-2008): Flora iberica. Plantas vasculares de la Península Ibérica e Islas Baleares. Madrid. Real Jardín Botánico. CSIC. 13 Vols.

COSTA, M. (1997): Biogeografía. En Izco, J. et al.: Botánica. Madrid. McGraw- Hill, 638-742.

CHYTRÝ, M. et al. (2008): Habitat invasions by alien plants: a quantitative comparison among Mediterranean, subcontinental and oceanic regions of Europe. Journal of Applied Ecology, 45, 448-458.

DAEHLER, C.C. (1998): The taxonomic distribution of invasive angiosperm plants: ecological insights and comparison to agricultural weeds. Biological Conservation, 84, 167-180.

GARCÍA-ABAD, J.J. (2006): El inventario florístico con fines geográficos en C.U.T.M. de $1 \times 1 \mathrm{~km}$. Análisis de la riqueza vascular en La Alcarria Occidental y Mesa de Ocaña. Serie Geográfica, 13, 117-150. 
GARCÍA-ABAD, J.J. (2009): Geografía de las plantas en La Alcarria Occidental y Mesa de Ocaña (I). Análisis florístico en cinco localidades representativas. Anales de Geografía de la Universidad Complutense, 29 (2), 127-153.

GARCÍA-ABAD, J.J. (2011): Geografía de las plantas en La Alcarria Occidental y Mesa de Ocaña (II). Análisis fitoecológico y biotípico de la flora autóctona en cinco localidades representativas. Anales de Geografía de la Universidad Complutense, 31 (2), 103-124.

GARCÍA-ABAD, J.J., RODRÍGUEZ, V.M. y GÓMEZ, M. (2009): Valoración territorial de prioridad para la protección, según la flora vascular amenazada y endémica. Aplicación a un sector de la Alta Alcarria de Guadalajara (Castilla-La Mancha). En Real, R. y Márquez, A.L. (Eds.): Biogeografía. "Scientia Biodiversitatis”. Málaga. Universidad de Málaga. Ministerio de Ciencia y Tecnología. Junta de Andalucía, 207-216.

GIL, T. y COSTA, M. (2003): Catálogo de la flora vascular de la Escombrera de la Mina de As Pontes de García Rodríguez (A Coruña, España). Ecología, 17: 161-176.

HULME, P.E. (2008): Contrasting alien and native plant species-area relationships: the importance of spatial grain and extent. Global Ecology and Biogeography, 17, 641647.

IZCO, J. (1969): Contribución al estudio de la flora y vegetación de las comarcas de Arganda y Chinchón (Madrid). Hoja 583. I.G.C. Madrid. Tesis Doctoral. Universidad Complutense de Madrid. Facultad de Farmacia.

KOLAR, C.S. y LODGE, D.M. (2001): Progress in invasion biology: predicting invaders. Trends in Ecology and Evolution, 16 (4), 199-204.

LAORGA, S. (1986): Estudio de la flora y vegetación de las comarcas toledanas del tramo central de la Cuenca del Tajo. Madrid. Tesis Doctoral. Universidad Complutense de Madrid. Facultad de Farmacia.

LARSON, D.L. et al. (2011): A framework for sustainable invasive species management: Environmental, social and economic objectives. Journal of Environmental Management, 92, 14-22.

LA SORTE, F.A. et al. (2008): Distance decay of similarity among European urban floras: the impact of anthropogenic activities on $\beta$ diversity. Global Ecology and Biogeography, 17, 363-371.

LÁZARO, J.A. (2007): Análisis biogeográfico de la flora vascular del tramo bajo del Valle de Esgueva (Valladolid, España). Toll Negre, 9, 23-32.

LODGE, D.M. (1993): Biological invasions: lessons for ecology. Trends in Ecology and Evolution, 8, 133-137.

MATEO, G. (1998): La flora del Sistema Ibérico: estado actual de nuestros conocimientos y perspectivas de futuro. Flora Montiberica, 10: 20-30.

MATEO, G. y CRESPO, M.B. (2002): Reflexiones sobre las afinidades biogeográficas de la flora de la Cordillera Ibérica. Flora Montiberica, 21, 6-17.

MEAZA, G. -ed.- (2000): Metodología y práctica de la Biogeografía. Editorial del Serbal. Barcelona. 
McNEELY, J.A. (2001): The great reshuffling: Human dimensions of invasive alien species. IUCN, Gland, Switzerland and Cambridge.

MELENDO, M., GIMÉNEZ, E., CANO, E., GÓMEZ-MERCADO, F. y VALLE, F. (2003): The endemic flora in the south of the Iberian Peninsula: taxonomic composition, biological spectrum, pollination, reproductive mode and dispersal. Flora, 198, 260-276.

MOLERO, J., SÁEZ, Ll. y VILLAR, L. (1998): Interés florístico y geobotánico de la Sierra de Alcubierre (Monegros, Aragón). Acta Botanica Barcinonensia, 45, 363390.

MOTA, J.F., SÁNCHEZ-GÓMEZ, P. y GUIRADO, J.S. -eds.-, (2011): Diversidad vegetal de las yeseras ibéricas. El reto de los archipiélagos edáficos para la biología de la conservación. Almería. ADIF-Mediterráneo Asesores Consultores.

NAVARRO, F.B., JIMÉNEZ, M.N., RIPOLL, M.A., BOCIO, I. y SIMÓN, E. De (2003): "Análisis de la riqueza florística en cultivos agrícolas abandonados de la Depresión de Guadix-Baza (Granada)". Monografías de Flora y Vegetación Béticas, 13, 17-34.

PANAREDA, J.M. y BOCCIO, M. (2009): Característiques biogeogràfiques de la flora vascular del Parc del Foix. II Trobada d'Estudiosos del Foix. Barcelona. Diputació de Barcelona, 137-144.

PAUCHARD, A. y SHEA, K. (2006): Integrating de study of non-native plant invasions across spatial scales. Biological invasions, 8, 399-413.

PEINADO, M., MONJE, L. y MARTÍNEZ, J.M. (2008): El paisaje vegetal de Castilla-La Mancha. Manual de Geobotánica. Toledo. Editorial Cuarto Centenario.

PEÑAS, J., MARTÍNEZ, A., JOSÉ, A. y MOTA, J.F. (2006): Análisis corológico y novedades florísticas de la Sierra de los Filabres (Andalucía Oriental, España). Lagascalia, 26, 51-70.

PYŠEK, P. et al. (2004): Alien plants in cheklists and floras: towards better communication between taxonomists and ecologists. Taxon, 53, 131-143.

RIVAS-MARTÍNEZ, S. y Cols. (2007): Mapa de series, geoseries y geopermaseries de vegetación de España (Memoria del mapa de vegetación potencial de España). Parte I. Itinera Geobotanica, 17, 5-436.

RON, M.E. (1970): Estudio sobre la vegetación y flora de La Alcarria. Tesis Doctoral inédita. Universidad Complutense de Madrid. Facultad de Ciencias (Sección Biológicas).

ROSENZWEIG, M.L. (2001): The four questions: What does the introduction of exotic species do to diversity? Evolutionary Ecology Research, 3, 361-367.

SANZ, M., DANA, E. y SOBRINO, E. (2004): Atlas de las plantas alóctonas invasoras de España. Madrid. Ministerio de Medio Ambiente.

Páginas Web:

ANTHOS: http://www.anthos.es. Sistema de información sobre las plantas de España. Fundación biodiversidad. Real Jardín Botánico. CSIC. [Consultas habituales y continuadas hasta junio de 2012]. 
ATLAS DE LA FLORA DE ARAGÓN. Herbario de Jaca: http://www.proyectos.ipe.csic.es/floragon/index.php. Gobierno de Aragón. IPE. CSIC. [Consultas habituales y continuadas hasta junio de 2012].

FLORA IBERICA: http://www.floraiberica.org. Flora iberica. Plantas vasculares de la Península Ibérica e Islas Baleares. Real Jardín Botánico. CSIC. Incorpora nuevos datos a los de Castroviejo (1986-2008). Se consultaron todos los borradores y pruebas de imprenta del resto de volúmenes, según fueron apareciendo desde 2009. [Consultas habituales y continuadas hasta junio de 2012].

\section{ANEXO \\ Listado de táxones (192) y nothotáxones (2) vasculares alóctonos referenciados en La Alcarria Occidental y Mesa de Ocaña (AM).}

Las plantas están ordenadas por orden alfabético dentro de cada familia (según el sistema taxonómico empleado en "Flora Ibérica" -véase web-).

Se incluyen: a) naturalizados (arqueófitos y neófitos) y adventicios, independientemente de que también puedan aparecer cultivados o escapados de cultivo; b) Plantas leñosas o herbáceas vivaces (fanerófitos) que se cultivan o han sido cultivados con fines agrícolas, ganaderos, ornamentales u otros. Se considera tanto la presencia, aunque sea efímera, por cultivo directo como por haberse encontrado cimarrones o pequeñas poblaciones espontáneas. No se incluyen las numerosas plantas herbáceas directamente cultivadas, salvo cuando las hayamos encontrado o existan referencias de ellas asilvestradas, escapadas de cultivo en hábitats diferentes al del propio cultivo o en años posteriores al de su cultivo. Nuestras prospecciones no incluyeron ámbitos urbanos, recintos/parcelas vallados y otras áreas o puntos de accesibilidad restringida. Las plantas subrayadas fueron avistadas en el transecto 5C. Las 31 plantas precedidas por asterisco $(*)$ son invasoras en la Península Ibérica según Sanz et al. (2004); la precedida por "+" significa que no se descarta su carácter autóctono. Binomen con "cf" (confer), presencia a confirmar; con " $\times ”$, nothotaxon (híbrido). Fuente: Extracto de la base de datos recopilada hasta IX-2008 (García-Abad, 2006 y 2009).

\section{Aceraceae}

Acer campestre

*Acer negundo

Acer platanoides

Acer pseudoplatanus

Agavaceae

*Agave americana

Yucca aloifolia

Amaranthaceae

*Amaranthus albus
*Amaranthus blitoides

Amaranthus deflexus

*Amaranthus hybridus

Amaranthus hypochondriacus

*Amaranthus murica-

tus

*Amaranthus powellii

*Amaranthus retro-

flexus
Anacardiaceae

Rhus coriaria

Apocynaceae

Nerium oleander

*Vinca difformis

Berberidaceae

Berberis vulgaris

Mahonia aquifolium 
Betulaceae

Corylus avellana

Bignoniaceae

Catalpa bignonioides

Boraginaceae

Asperugo procumbens

Cactaceae

*Opuntia ef praeacantha

Cannabaceae

Cannabis sativa

Cannaceae

Canna indica

Caprifoliaceae

Lonicera japonica

Caryophyllaceae

Agrostemma githago

Gypsophila pilosa

Lychnis viscaria

Celastraceae

Euonymus japonicus

Chenopodiaceae

Atriplex hortensis

Atriplex sagittata

Beta vulgaris

Chenopodium ambrosioides

Chenopodium multifidum

Halogeton sativus

\section{Commelinaceae}

Tradescantia virginiana
Compositae

Artemisia abrontanum

*Aster squamatus

Centaurea cyanus

Centaurea depressa

*Conyza bonariensis

*Conyza canadensis

Crepis bursifolia

Cynara scolymus

Helianthus annuus

Tanacetum vulgare

*Xanthium italicum

Xanthium orientale

*Xanthium spinosum

*Xanthium strumarium

Convolvulaceae

Cuscuta campestris

Crassulaceae

Sempervivum tectorum

Cruciferae

Brassica napus

Brassica oleracea

Camelina alyssum

Conringia orientalis

*Isatis tinctoria

\section{Cucurbitaceae}

Citrullus lanatus

Cucumis melo

Cucumis myriocarpus

Cucumis sativus

Cucurbita maxima

Cucurbita pepo

\section{Cupressaceae}

Cupressus arizonica

Cupressus sempervirens

Platycladus orientalis
Dipsacaceae

Cephalaria syriaca

Dipsacus sativus

Eleagnaceae

*Eleagnus angustifolia

Euphorbiaceae

Chamaesyce prostrata

Euphorbia lathyris

\section{Gramineae}

*Arundo donax

Avena sativa

*Bromus catharticus

*Cortaderia selloana

Echinochloa crus-galli

Hordeum vulgare

Lolium temulentum

*Paspalum dilatatum

Phalaris canariensis

Phyllostachys viridiglaucescens

Polypogon monspeliensis

Rostraria pumila

Saccharum ravennae

Setaria pumila

Setaria viridis

Sorghum bicolor

*Sorghum halepense

Triticum aestivum

Triticum durum

Hippocastanaceae

Aesculus hippocastanum

Hydrangeaceae

Philadelphus pubescens

Iridaceae

Iris germanica 
Juglandaceae

Juglans regia

Labiateae

Melissa officinalis

Mentha spicata

Mentha $\times$ verticillata

Teucrium fruticans

Lauraceae

Laurus nobilis

Leguminosae

Cercis siliquastrum

Cicer arietinum

*Gleditschia triacanthos

Lathyrus sativus

Lens culinaris

Lupinus albus

Medicago sativa

Onobrychis viciifolia

Phaseolus vulgaris

Pisum sativum

*Robinia pseudoacacia

Sophora japonica

Spartium junceum

Vicia ervilia

Vicia faba

Vicia villosa

Liliaceae

Allium porrum

Asparagus officinalis

Ornithogalum nutans

Tulipa clusiana

Tulipa gesneriana

Malvaceae

*Abutilon theophrasti

Alcea rosea
Moraceae

Broussonetia papyrifera

Ficus carica

Morus alba

Morus nigra

Myrtaceae

*Eucalyptus globulus

Nyctaginaceae

Mirabilis jalapa

Oleaceae

+ Fraxinus excelsior

Jasminum officinale

Ligustrum lucidum

Olea europaea

Syringa vulgaris

Onagraceae

Epilobium brachycarpum

Oxalidaceae

Oxalis corniculata

Oxalis debilis subsp. corymbosa

Passifloraceae

Passiflora caerulea

Pinaceae

Cedrus atlantica

Pinus pinaster

Pinus pinea

Pinus sylvestris

Platanaceae

Platanus hispanicus

Platanus orientalis
Polygonaceae

*Fallopia baldschuanica

Rumex cristatus

Portulacaceae

Portulaca oleracea subsp. stellata

Punicaceae

Punica granatum

Ranunculaceae

Consolida ajacis

Resedaceae

Reseda odorata

Rosaceae

Cydonia oblonga

Malus domestica

Prunus armeniaca

Prunus avium

Prunus cerasifera

Prunus cerasus

Prunus domestica

Prunus dulcis

Prunus persica

Pyracantha coccinea

Pyrus communis

Pyrus cordata

Rosa moschata

Rubiaceae

Rubia tinctorum

Salicaceae

Populus nigra

Populus pyramidalis

Populus $\times$ canadensis

Salix babilonica 
Sapindaceae

Koelreuteria paniculata

\section{Scrophulariacae}

Cymbalaria muralis

Veronica peregrina

Veronica persica

Veronica polita

Simaroubaceae

*Ailanthus altissima

Solanaceae

Datura ferox

*Datura stramonium

Lycium afrum

Lycium barbarum
Physalis ixocarpa

Physalis of philadelphica

Solanum lycopersicum

Tamaricaceae

Tamarix parviflora

Tiliaceae

Tilia platyphyllos

Ulmaceae

Celtis australis

Ulmus pumila

Umbelliferae

Anethum graveolens

Bupleurum fruticosum
Coriandrum sativum

Pimpinella anisum

Valerianaceae

Centranthus angustifolius

Verbenaceae

Vitex agnus-castus

Violaceae

Viola odorata

Vitaceae

Vitis vinifera

Zygophyllaceae

*Zygophyllum fabago 